\title{
3-Mercaptopropanol as Traceless Linker for Chemical and Enzymatic Synthesis of Oligosaccharides
}

\author{
Nabyl Merbouh, Fredrik K. Wallner, Oana M. Cociorva and Peter H. Seeberger ${ }^{\S *}$, \\ The Burnham Institute for Medical Research, 10901 N. Torrey Pines Road, La Jolla, CA 92037 \\ pseeberg@burnham.org \\ ${ }^{\S}$ Alternative address: Laboratory for Organic Chemistry, ETH Zurich, Wolfgang-Pauli-Str.10, HCI F315, 8093 Zurich, \\ Switzerland.
}

\section{Supplementary Material}

\section{Table of Contents}

Page

Experimental Section: General

S 2

Preparation of allyl ethers and esters 4, 5 and $\mathbf{8}$

S 2

General procedure for the photochemical synthesis of glucose derivatives 9a-9f and glucosamine derivatives 10a-10d

Enzymatic preparation of the lactose and lactosamine derivatives 11d and 12d

S 9

Chemical glycosylations: synthesis of derivatives 13, 14 and 15

References

S 12

Spectra

S 13 


\section{Experimental Section}

General. All solvents and reagents used were reagent grade or better and were used as received. The analytical thin-layer chromatography plates were performed on Merck silica gel $60 \mathrm{~F}_{254}$ plates (glass backed, $0.25 \mathrm{~mm}$ ). Compounds were visualized by dipping the plates in a cerium sulfateammonium molybdate solution or $10 \% \mathrm{H}_{2} \mathrm{SO}_{4}$ in $\mathrm{MeOH}$, followed by heating. Liquid column chromatography was performed using forced flow on silica gel (standard grade, $60 \AA$, 32-70 $\mu \mathrm{m}$ )

unless otherwise stated. ${ }^{1} \mathrm{H}$ NMR and ${ }^{13} \mathrm{C}$ NMR were recorded on a Varian Inova 300, a Bruker AC300F, or a Bruker Avance 600, and were referenced to residual solvent peaks. High resolution FAB mass spectra were provided by the Mass Spectrometry Facility, Department of Chemistry and Biochemistry, University of Notre-Dame. The ESI/MS spectra were recorded on a Waters Micromass ZQ. The microscale photochemical reactor used was purchased from Ace Glass and equipped with a quartz well. The Mercury lamp (254 nm) with its power supply was purchased from UVP. Reversed phase purifications were performed on serially connected SepPak ${ }^{\circledR}$ Plus C18 cartridges from Waters Corporation.

Compounds $(\mathbf{1})^{1},(2)^{2},(3)^{3},(6)^{4}$, and $(7)^{5}$ were prepared according to literature procedures.

Allyl 1-naphthoate (4): To a solution of allyl alcohol (1.16 g, $20 \mathrm{mmol})$ and pyridine $(1.6 \mathrm{~mL})$ in dichloromethane $(50 \mathrm{~mL})$ was added a solution of 1-naphthoyl chloride $(1.90 \mathrm{~g}, 10 \mathrm{mmol})$ in dichloromethane $(50 \mathrm{~mL})$ dropwise, at room temperature, over $30 \mathrm{~min}$. The mixture was further stirred. After one hour, TLC showed almost quantitative conversion of the acyl chloride to the corresponding allyl ester. 
This reaction is difficult to monitor by TLC since starting material and product exhibit similar Rf. However, the ester can be visualized using a cerium sulfate-ammonium molybdate solution, while the starting material does not. The reaction was quenched by addition of water in small portions, and the solvent was removed under vacuum. The resulting oil was partitioned between water $(50 \mathrm{~mL})$ and dichloromethane $(50 \mathrm{~mL})$, and the aqueous phase was further extracted with dichloromethane $(2 \times 50 \mathrm{~mL})$. The organic phase was dried $\left(\mathrm{Na}_{2} \mathrm{SO}_{4}\right)$ and the solvent removed under vacuum. The resulting allyl ester was purified by chromatography on silica gel (hexane/EtOAc 3:2) to yield an oil (average yield $70 \%$ ). $\mathrm{Rf}=0.80$ ( silica, hexane/EtOAc 3:2); ${ }^{1} \mathrm{H}$ NMR $\left(300 \mathrm{MHz}, \mathrm{CDCl}_{3}\right): \delta 8.93(\mathrm{~d}, 1 \mathrm{H}, J=8.7 \mathrm{~Hz}), 8.21(\mathrm{dd}, 1 \mathrm{H}, J=7.2,1.5 \mathrm{~Hz}), 7.99(\mathrm{~d}, 1 \mathrm{H}, J=$ 8.4 Hz), $7.85(\mathrm{~d}, 1 \mathrm{H}, J=8.4 \mathrm{~Hz}), 7.63-7.44(\mathrm{~m}, 3 \mathrm{H}), 6.16-6.03(\mathrm{~m}, 1 \mathrm{H}), 5.45(\mathrm{dq}, 1 \mathrm{H}, J=17.1,1.5$ $\mathrm{Hz}), 5.31(\mathrm{dq}, 1 \mathrm{H}, J=10.5,1.2 \mathrm{~Hz}), 4.91(\mathrm{dt}, 2 \mathrm{H}, J=5.7,1.5 \mathrm{~Hz}) ;{ }^{13} \mathrm{C} \mathrm{NMR}\left(75 \mathrm{MHz}, \mathrm{CDCl}_{3}\right): \delta$ $167.4,134.0,133.6,132.5,131.6,130.5,128.8,128.0,127.2,126.4,126.0,124.7,118.6,65.9$; HRMS (FAB+ of MH+, PEG): m/z calcd for $\mathrm{C}_{14} \mathrm{H}_{13} \mathrm{O}_{2}: 213.0916$, found: 213.0918 .

1-Naphthalenemethanol allyloxyethanol ether (5): To a solution of 2-allyloxyethanol (1.02 g, 10 $\mathrm{mmol})$ in DMF $(30 \mathrm{~mL})$ was added $\mathrm{NaH}(0.5 \mathrm{~g}, 60 \%$ dispersion in paraffin) previously washed with hexane $(3 \times 10 \mathrm{~mL})$ in small portions, at room temperature, for $30 \mathrm{~min}$. To the well-stirred mixture 2-(bromomethyl)naphthalene $(2.21 \mathrm{~g}, 10 \mathrm{mmol})$ was added and the mixture was further stirred. After one hour the reaction was quenched by addition of water in small portions, and the solvent was removed under vacuum. The resulting oil was partitioned between water $(50 \mathrm{~mL})$ and dichloromethane $(50 \mathrm{~mL})$, and the aqueous phase further extracted with dichloromethane $(2 \times 50$ $\mathrm{mL})$. The organic phase was dried $\left(\mathrm{Na}_{2} \mathrm{SO}_{4}\right)$ and the solvent removed under vacuum. The resulting ally ether was purified by chromatography on silica gel (hexane/EtOAc $4: 1$ ) to yield $65 \%$ of an oil. 
$\mathrm{Rf}=0.75$ (silica, hexane/EtOAc 3:2); ${ }^{1} \mathrm{H}$ NMR $\left(300 \mathrm{MHz}, \mathrm{CDCl}_{3}\right): \delta$ 7.83-7.78 (m, 4H), 7.50-7.42 (m, 3H), 6.00-5.87 (m, 1H), $5.28(\mathrm{dq}, 1 \mathrm{H}, J=17.4,1.5 \mathrm{~Hz}), 5.18(\mathrm{dq}, 1 \mathrm{H}, J=10.2,1.2 \mathrm{~Hz}), 4.73(\mathrm{~s}$, $2 \mathrm{H}), 4.00(\mathrm{td}, 2 \mathrm{H}, J=5.7,1.2 \mathrm{~Hz}), 3.70-3.60(\mathrm{~m}, 4 \mathrm{H}) ;{ }^{13} \mathrm{C} \mathrm{NMR}\left(75 \mathrm{MHz}, \mathrm{CDCl}_{3}\right): \delta 136.0,135.0$, $133.5,133.2,128.3,128.0,127.9,126.7,126.3,126.0,125.9,117.3,73.7,77.3,76.8,69.7,69.6$; HR-MS (FAB+ of M+, PEG): m/z calcd for $\mathrm{C}_{16} \mathrm{H}_{18} \mathrm{O}_{2}: 242.1307$, found: 242.1230 .

Biotin allyl ester (8): D-(+)-Biotin $(0.5 \mathrm{~g}, 2.0 \mathrm{mmol})$ was dissolved in neat allyl alcohol $(25 \mathrm{~mL})$, and Amberlyst resin $\left(120 \mathrm{H}^{+}, 2 \mathrm{~g}\right.$, freshly dried) was added. The mixture was gently refluxed for one hour before a few drops of $\mathrm{H}_{2} \mathrm{SO}_{4}$ (conc.) were carefully added and the mixture further refluxed overnight. The reaction was cooled, filtered and made neutral by addition of $\mathrm{NaOH}(3 \mathrm{M})$. The solvent was removed under vacuum, and the resulting allyl ester was purified by silica gel column chromatography to yield $52 \%$ of a white solid. ${ }^{1} \mathrm{H}$ NMR (300 MHz, $\left.\mathrm{CDCl}_{3}\right): \delta 6.00$ (bs, $\left.1 \mathrm{H}\right), 5.98$ $5.85(\mathrm{~m}, 1 \mathrm{H}), 5.68(\mathrm{bs}, 1 \mathrm{H}), 5.34-5.22(\mathrm{~m}, 2 \mathrm{H}), 4.58-4.48(\mathrm{~m}, 3 \mathrm{H}), 4.3(\mathrm{~m}, 1 \mathrm{H}), 3.15(\mathrm{~m}, 1 \mathrm{H}), 2.91$ $(\mathrm{dd}, 1 \mathrm{H}, J=12,3 \mathrm{~Hz}), 2.74(\mathrm{~d}, 1 \mathrm{H}, J=12 \mathrm{~Hz}), 2.36(\mathrm{t}, 2 \mathrm{H}, J=9 \mathrm{~Hz}), 1.76-1.40(\mathrm{~m}, 6 \mathrm{H}) ;{ }^{13} \mathrm{C} \mathrm{NMR}$ (75 MHz, $\left.\mathrm{CDCl}_{3}\right): \delta 173.5,164.0,132.4,118.5,77.0,65.3,62.1,60.3,55.7,40.8,34.0,28.3,25.0$; HR-MS (FAB+ of MH+, PEG): m/z calcd for $\mathrm{C}_{13} \mathrm{H}_{21} \mathrm{~N}_{2} \mathrm{O}_{3} \mathrm{~S}: 285.1273$, found: 285.1255. 
General procedure for the preparation of glucose derivatives 9a-9f. To a solution of tetraacetyl$\beta$-1-thio-glucopyranose $(0.5 \mathrm{~g}, 1.38 \mathrm{mmol})$ in methanol $(15 \mathrm{~mL})$ was added allyl ester or allyl ether derivative (1.2 2 equiv.), and the solution was transferred into a photochemical cell. The solution was flushed with $\mathrm{N}_{2}$ for $15 \mathrm{~min}$. and exposed to UV light (Mercury lamp $254 \mathrm{~nm}$ ) through a quartz well. The solution was irradiated until the TLC (silica gel, hexane/EtOAc 3:2) showed no remaining sugar (most reactions were almost complete after about $4 \sim 6$ hours). The solution was then transferred into an Erlenmeyer flask $(50 \mathrm{~mL})$ and a freshly prepared solution of sodium methoxide in methanol was added to reach $\mathrm{pH} 11$. The solution was stirred until cleavage of acetate esters was complete (as assessed by TLC). The methanolic solution was then filtered through a short plug of silica gel, and the solvent removed under vacuum. The resulting solid/oil was dissolved in a minimum amount of water $(8 \mathrm{~mL}$ max.), charged onto a heavy solvent extractor, and continuously extracted with dichloromethane overnight. The dichloromethane phase was subsequently evaporated and the residue purified by chromatography (short column, silica gel, EtOAc/MeOH 8:1) to yield the desired compound as either a solid or oil. The compounds where found to be stable, and where freeze-dried. Compounds $9 \mathbf{e}$ and $\mathbf{9 f}$ were not deacetylated but instead isolated by chromatography.

The preparation of the glucosamine derivatives (10a-10d) followed the preparation of the gluocose derivatives using 2 -acetamido-2-deoxy-3,4,6-tri-O-acetyl-1-thio- $\beta$-D-glucopyranose (2) as starting material.

Compound 9a: ${ }^{1} \mathrm{H}$ NMR (300 MHz, $\left.\mathrm{CD}_{3} \mathrm{OD}\right): \delta 8.22-8.19(\mathrm{~m}, 1 \mathrm{H}), 7.78-7.74(\mathrm{~m}, 1 \mathrm{H}), 7.47-7.31$ $(\mathrm{m}, 4 \mathrm{H}), 6.88(\mathrm{~d}, 1 \mathrm{H}, J=7.2 \mathrm{~Hz}), 4.38(\mathrm{~d}, 1 \mathrm{H}, J=9.3 \mathrm{~Hz}), 4.26(\mathrm{t}, 2 \mathrm{H}, J=6 \mathrm{~Hz}), 3.81(\mathrm{dd}, 1 \mathrm{H}, J=$ $12,2.1 \mathrm{~Hz}), 3.65-3.56(\mathrm{~m}, 1 \mathrm{H}), 3.31-3.26(\mathrm{~m}, 2 \mathrm{H}), 3.23-3.16(\mathrm{~m}, 2 \mathrm{H}) 3.09-2.90(\mathrm{~m}, 2 \mathrm{H}), 2.24$ 
(quintet, $2 \mathrm{H}, J=6.3 \mathrm{~Hz}) ;{ }^{13} \mathrm{C} \mathrm{NMR}\left(75 \mathrm{MHz}, \mathrm{CD}_{3} \mathrm{OD}\right): \delta 155.5,135.7,128.3,127.1,126.9,126.7$, $125.9,122.6,120.9,105.7,87.1,81.6,79.3,74.1,71.0,67.3,62.6,30.8,27.7$; HR-MS (FAB+ of $\mathrm{M}+, \mathrm{PEG}): \mathrm{m} / \mathrm{z}$ calcd for $\mathrm{C}_{19} \mathrm{H}_{24} \mathrm{O}_{6} \mathrm{~S}: 380.1294$, found: 380.1284 .

Compound 9b: ${ }^{1} \mathrm{H}$ NMR (300 MHz, $\left.\mathrm{CD}_{3} \mathrm{OD}\right): \delta 8.82(\mathrm{~d}, 1 \mathrm{H}, J=8.7 \mathrm{~Hz}), 8.11(\mathrm{~d}, 1 \mathrm{H}, J=7.2 \mathrm{~Hz})$, $7.99(\mathrm{~d}, 1 \mathrm{H}, J=8.1 \mathrm{~Hz}), 7.86(\mathrm{~d}, 1 \mathrm{H}, J=8.1 \mathrm{~Hz}), 7.60-7.43(\mathrm{~m}, 3 \mathrm{H}), 4.51-4.44(\mathrm{~m}, 3 \mathrm{H}), 3.88(\mathrm{dd}$, $1 \mathrm{H}, J=12.3,1.5 \mathrm{~Hz}$ ), 3.73-3.67 (m, 1H), 3.48-3.27 (m, 4H), 3.00-2.80 (m, 2H), 2.14 (quintet, $2 \mathrm{H}, J$ $=6.6 \mathrm{~Hz}) ;{ }^{13} \mathrm{C}$ NMR $\left(75 \mathrm{MHz}, \mathrm{CD}_{3} \mathrm{OD}\right): \delta 186.7,135.0,134.3,132.2,131.0,129.5,128.5,128.0$, 127.0, 126.4, 125.4, 87.0, 81.7, 79.3, 74.1, 71.1, 64.7, 62.6, 30.1, 27.5; HR-MS (FAB+ of MH+, PEG): $\mathrm{m} / \mathrm{z}$ calcd for $\mathrm{C}_{20} \mathrm{H}_{25} \mathrm{O}_{7} \mathrm{~S}: 409.1321$, found: 409.1324 .

Compound 9c: ${ }^{1} \mathrm{H}$ NMR $\left(300 \mathrm{MHz}, \mathrm{CD}_{3} \mathrm{OD}\right): \delta$ 7.85-7.79 (m, 4H), 7.49-7.43 (m, 3H), $4.67(\mathrm{~s}$, 2H), $4.37(\mathrm{~d}, 1 \mathrm{H}, J=9.6 \mathrm{~Hz}), 3.84(\mathrm{dd}, 1 \mathrm{H}, J=12,2.1 \mathrm{~Hz}), 3.68-3.55(\mathrm{~m}, 7 \mathrm{H}), 3.38-3.20(\mathrm{~m}, 4 \mathrm{H})$, $2.80(\mathrm{~m}, 2 \mathrm{H}), 1.90$ (quintet, $2 \mathrm{H}, J=12.9 \mathrm{~Hz}) ;{ }^{13} \mathrm{C}$ NMR $\left(75 \mathrm{MHz}, \mathrm{CD}_{3} \mathrm{OD}\right.$ ): $\delta$ 137.0, 134.6, 134.3, $129.0,128.8,128.5,127.4,127.0,126.8,126.7,87.0,81.8,79.4,74.2,74.0,71.3,71.0,70.5,70.4$, 62.7, 31.0, 27.6; ESI-MS: M+H: 439, M+Na: 461.

Compound 9d: ${ }^{1} \mathrm{H}$ NMR (300 MHz, $\left.\mathrm{CD}_{3} \mathrm{OD}\right): \delta 7.77(\mathrm{~d}, 1 \mathrm{H}, J=9.6 \mathrm{~Hz}), 7.42(\mathrm{~d}, 1 \mathrm{H}, J=8.1 \mathrm{~Hz})$, $6.85(\mathrm{~d}, 1 \mathrm{H}, J=2.4 \mathrm{~Hz}), 6.82(\mathrm{~s}, 1 \mathrm{H}), 6.13(\mathrm{~d}, 1 \mathrm{H}, J=9.3 \mathrm{~Hz}), 4.27(\mathrm{~d}, 1 \mathrm{H}, J=9.6 \mathrm{~Hz}), 4.11(\mathrm{t}, 2 \mathrm{H}$, $J=6 \mathrm{~Hz}), 3.74(\mathrm{dd}, 1 \mathrm{H}, J=12.3,1.8 \mathrm{~Hz}), 3.53(\mathrm{dd}, 1 \mathrm{H}, J=12,5.4 \mathrm{~Hz}), 3.26-3.06(\mathrm{~m}, 4 \mathrm{H}), 2.81$ (m, 2H), 2.04 (quintet, $2 \mathrm{H}, J=6.3 \mathrm{~Hz}) ;{ }^{13} \mathrm{C}$ NMR $\left(75 \mathrm{MHz}, \mathrm{CD}_{3} \mathrm{OD}\right): \delta$ 163.8, 163.3, 157.0, 145.7, 130.3, 114.1, 113.9, 113.2, 102.2, 87.2, 81.9, 79.5, 74.3, 71.3, 68.0, 62.8, 30.5, 27.4; HR-MS (FAB+ of $\mathrm{MH}+, \mathrm{PEG}): \mathrm{m} / \mathrm{z}$ calcd for $\mathrm{C}_{18} \mathrm{H}_{23} \mathrm{O}_{8} \mathrm{~S}: 399.1114$, found: 399.1094 . 
Compound 9e: ${ }^{1} \mathrm{H}$ NMR $\left(300 \mathrm{MHz}, \mathrm{CDCl}_{3}\right): \delta 8.02(\mathrm{~d}, 1 \mathrm{H}, J=7.2 \mathrm{~Hz}), 7.73-7.56(\mathrm{~m}, 2 \mathrm{H}), 7.17$ (d, $1 \mathrm{H}, J=7.1 \mathrm{~Hz}), 6.81-6.47(\mathrm{~m}, 6 \mathrm{H}), 5.23(\mathrm{t}, 1 \mathrm{H}, J=9.3 \mathrm{~Hz}), 5.07(\mathrm{q}, 2 \mathrm{H}, J=9.4 \mathrm{~Hz}), 4.52(\mathrm{~d}, 1 \mathrm{H}, J$ $=10.0 \mathrm{~Hz}), 4.22(\mathrm{dd}, 1 \mathrm{H}, J=12.3,4.8 \mathrm{~Hz}), 4.18-4.02(\mathrm{~m}, 3 \mathrm{H}), 3.75-3.63(\mathrm{~m}, 1 \mathrm{H}), 2.97-2.75(\mathrm{~m}$, 2H), 2.17-1.98 (m, 14H); $\left.{ }^{13} \mathrm{C} \mathrm{NMR} \mathrm{(166} \mathrm{MHz,} \mathrm{CDCl}_{3}\right): \delta 180.0,170.9,170.5,169.9-169.7(3$ carbons), 160.7, 158.0, 153.3, 152.7, 152.6, 135.3, 129.9, 129.6, 129.3, 127.0, 125.2, 124.2, 112.5, $112.3,111.5,103.3,101.5,84.1,84.0,76.1,74.0,70.0,68.5,66.5,62.3,29.4,27.1,20.9-20.8(4$ carbons); HR-MS (FAB+ of M+, PEG): m/z calcd for $\mathrm{C}_{37} \mathrm{H}_{37} \mathrm{O}_{14} \mathrm{~S}: 737.1904$, found: 737.1929 .

Compound 9f: ${ }^{1} \mathrm{H}$ NMR (300 $\left.\mathrm{MHz}, \mathrm{CDCl}_{3}\right): \delta 5.7(\mathrm{~s}, 1 \mathrm{H}), 5.29(\mathrm{~s}, 1 \mathrm{H}), 5.23(\mathrm{t}, 1 \mathrm{H}, J=9.3 \mathrm{~Hz})$, 5.13-5.00 (m, 2H), 4.54-4.48 (m, 2H), 4.34-4.30 (m, 1H), 4.27-4.21 (m, 1H), 4.17-4.10 (m, 3H), 3.76-3.69 (m, 1H), 3.20-3.12 (m, 1H), 2.96-2.88 (m, 1H), 2.83-2.65 (m, 3H), $2.34(\mathrm{t}, 2 \mathrm{H}, J=7.5$ Hz), 2.10-2.01 (4 singlets, 12H), 1.99-1.90 (m, 2H), $1.84(\mathrm{~s}, 1 \mathrm{H}), 1.75-1.62(\mathrm{~m}, 4 \mathrm{H}), 1.50-1.42(\mathrm{~m}$, $2 \mathrm{H}) ;{ }^{13} \mathrm{C} \mathrm{NMR}\left(75 \mathrm{MHz}, \mathrm{CDCl}_{3}\right): \delta 173.8,170.8,170.4,169.7,163.6,83.7,76.0,73.9,69.8,68.4$, 62.9, 62.3, 62.1, 60.3, 55.8, 40.7, 34.0, 29.1, 28.5, 28.4, 26.8, 25.0, 21.0-20.8 (4 carbons); ESI-MS: M+H: 649, M+Na: 671.

Compound 10a: ${ }^{1} \mathrm{H}$ NMR $\left(300 \mathrm{MHz}, \mathrm{DMSO}-d_{6}\right): \delta 8.17(\mathrm{~d}, 1 \mathrm{H}, J=7.2 \mathrm{~Hz}), 7.84(\mathrm{~d}, 1 \mathrm{H}, J=6.9$ Hz), $7.72(\mathrm{~d}, 1 \mathrm{H}, J=9.3 \mathrm{~Hz}), 7.53-7.36(\mathrm{~m}, 4 \mathrm{H}), 6.94(\mathrm{~d}, 1 \mathrm{H}, J=7.2 \mathrm{~Hz}), 4.39(\mathrm{~d}, 1 \mathrm{H}, J=10.2 \mathrm{~Hz})$, $4.19(\mathrm{t}, 2 \mathrm{H}, J=6.3 \mathrm{~Hz}), 3.67(\mathrm{~d}, 1 \mathrm{H}, J=12 \mathrm{~Hz}), 3.53(\mathrm{q}, 1 \mathrm{H}, J=9.3 \mathrm{~Hz}), 3.44-3.25(\mathrm{~m}, 5 \mathrm{H}), 3.09$ $(\mathrm{m}, 2 \mathrm{H}), 2.94-2.78(\mathrm{~m}, 2 \mathrm{H}), 2.12(\mathrm{t}, 2 \mathrm{H}, J=7.2 \mathrm{~Hz}), 1.78(\mathrm{~s}, 3 \mathrm{H}) ;{ }^{13} \mathrm{C}$ NMR $\left(75 \mathrm{MHz}, \mathrm{DMSO}-d_{6}\right): \delta$ $168.9,153.9,134.0,127.4,126.4,126.2,125.2,124.9,121.6,119.8,105.0,84.3,81.2,75.4,70.4$, 
66.4, 61.1, 54.4, 29.1, 26.2, 23.1; HR-MS (FAB+ of MH+, PEG): $\mathrm{m} / \mathrm{z}$ calcd for $\mathrm{C}_{21} \mathrm{H}_{28} \mathrm{NO}_{6} \mathrm{~S}$ : 422.1637, found: 422.1651 .

Compound 10b: ${ }^{1} \mathrm{H}$ NMR $\left(300 \mathrm{MHz}, \mathrm{DMSO}-d_{6}\right): \delta 8.75(\mathrm{~d}, 1 \mathrm{H}, J=9.0 \mathrm{~Hz}), 8.22-8.17(\mathrm{~m}, 2 \mathrm{H})$, $8.04(\mathrm{~d}, 1 \mathrm{H}, J=9.0 \mathrm{~Hz}), 7.76-7.59(\mathrm{~m}, 4 \mathrm{H}), 5.03-4.98(\mathrm{~m}, 2 \mathrm{H}), 4.52(\mathrm{t}, 1 \mathrm{H}, J=6.0 \mathrm{~Hz}), 4.45-4.39$ (m, 3H), 3.71-3.65 (m, 1H), $3.52(\mathrm{q}, 1 \mathrm{H}, J=9.0 \mathrm{~Hz}), 3.44-3.27(\mathrm{~m}, 2 \mathrm{H}), 3.28(\mathrm{~m}, 2 \mathrm{H}), 2.87-2.73$ (m, 2H), 2.08-1.99 (m, 2H), $1.81(\mathrm{~s}, 3 \mathrm{H}) ;{ }^{13} \mathrm{C}$ NMR (75 MHz, DMSO- $\left.d_{6}\right): \delta$ 169.4, 167.3, 133.9, $133.8,130.9,130.4,129.2,128.3,127.2,126.8,125.5,125.4,84.7,81.7,76.0,71.0,64.2,61.6$, 55.0, 29.0, 26.5, 23.5; HR-MS (FAB+ of MH+, PEG): $\mathrm{m} / \mathrm{z}$ calcd for $\mathrm{C}_{22} \mathrm{H}_{28} \mathrm{NO}_{7} \mathrm{~S}: 450.1586$, found: 450.1586.

Compound 10c: ${ }^{1} \mathrm{H}$ NMR $\left(300 \mathrm{MHz}, \mathrm{DMSO}-d_{6}\right): \delta 7.91-7.82(\mathrm{~m}, 4 \mathrm{H}), 7.69(\mathrm{~d}, 1 \mathrm{H}, J=9 \mathrm{~Hz})$, 7.51-7.44 (m, 3H), 5.03-4.95 (m, 2H), $4.64(\mathrm{~s}, 2 \mathrm{H}), 4.49(\mathrm{t}, 1 \mathrm{H}, J=5.4 \mathrm{~Hz}), 4.32(\mathrm{~d}, 1 \mathrm{H}, J=10.2$ $\mathrm{Hz}), 3.67-3.20(\mathrm{~m}, 10 \mathrm{H}), 3.07(\mathrm{~s}, 2 \mathrm{H}), 2.71-2.54(\mathrm{~m}, 2 \mathrm{H}), 1.80-1.70(\mathrm{~m}, 5 \mathrm{H}) ;{ }^{13} \mathrm{C}$ NMR $(75 \mathrm{MHz}$, DMSO- $\left.d_{6}\right): \delta 168.9,136.1,132.8,132.4,127.8,127.7,127.6,126.1,125.8$ (2 carbons), 84.3, 81.2, 75.5, 72.0, 70.4, 69.5, 69.1, 66.0, 29.4, 29.1, 23.0; HR-MS (FAB+ of MH+, PEG): $\mathrm{m} / \mathrm{z}$ calcd for $\mathrm{C}_{24} \mathrm{H}_{34} \mathrm{NO}_{7} \mathrm{~S}: 480.2056$, found: 480.2033 .

Compound 10d: ${ }^{1} \mathrm{H}$ NMR $\left(300 \mathrm{MHz}, \mathrm{DMSO}-d_{6}\right): \delta 8.00(\mathrm{~d}, 1 \mathrm{H}, J=9.6 \mathrm{~Hz}), 7.74(\mathrm{~d}, 1 \mathrm{H}, J=9.3$ $\mathrm{Hz}), 7.63(\mathrm{~d}, 1 \mathrm{H}, J=8.4 \mathrm{~Hz}), 7.00-6.94(\mathrm{~m}, 2 \mathrm{H}), 6.29(\mathrm{~d}, 1 \mathrm{H}, J=9.6 \mathrm{~Hz}), 5.04(\mathrm{~d}, 1 \mathrm{H}, J=4.5 \mathrm{~Hz})$, $5.00(\mathrm{~d}, 1 \mathrm{H}, J=5.4 \mathrm{~Hz}), 4.53(\mathrm{t}, 1 \mathrm{H}, J=5.7 \mathrm{~Hz}), 4.38(\mathrm{~d}, 1 \mathrm{H}, J=10.5 \mathrm{~Hz}), 4.15(\mathrm{t}, 2 \mathrm{H}, J=6.3 \mathrm{~Hz})$, 3.72-3.40 (m, 3H), 3.29-3.23 (m, 1H), $3.10(\mathrm{bs}, 2 \mathrm{H}), 2.82-2.69(\mathrm{~m}, 2 \mathrm{H}), 2.04-1.95(\mathrm{~m}, 2 \mathrm{H}), 1.80(\mathrm{~s}$, $3 \mathrm{H}) ;{ }^{13} \mathrm{C}$ NMR (75 MHz, DMSO- $\left.d_{6}\right): \delta 168.9,161.7,160.3,155.4,144.3,129.5,112.7,112.4$, 
$112.3,101.2,84.2,81.2,75.5,70.4,67.0,61.2,54.5,28.8,25.8,23.0$; HR-MS (FAB+ of MH+, PEG): $\mathrm{m} / \mathrm{z}$ calcd for $\mathrm{C}_{20} \mathrm{H}_{26} \mathrm{NO}_{8} \mathrm{~S}: 440.1379$, found: 440.1371 .

\section{Enzymatic preparation of the lactose and lactosamine derivatives 11d and 12d.}

7-(3-(1-Thio-2,3,6,2',3',4',6'-O-heptaacetate lactosyl)-propyloxy)coumarin (11d)' ${ }^{6}$ : Compound 9d $(9.2 \mathrm{mg}, 23 \mu \mathrm{mol})$ and the disodium salt of uridine-5'-diphosphogalactose (UDP-Gal, $17.7 \mathrm{mg}$, $29 \mu \mathrm{mol})$ were dissolved in an aq. buffer $\left(6 \mathrm{mM}\right.$ in $\mathrm{MnCl}_{2}, 0.05 \mathrm{M}$ in sodium cacodylate, containing $0.1 \mathrm{mg} / \mathrm{mL} \alpha$-lactalbumin, $465 \mu \mathrm{L})$ and $\beta(1-4)$-galactosyltransferase $(0.23 \mathrm{U}, 23 \mu \mathrm{L}$ of a $10 \mathrm{U} / \mathrm{mL}$ stock solution in $50 \%$ glycerol) was added. The solution was stirred at $37^{\circ} \mathrm{C}$ for $96 \mathrm{~h}$ and diluted with water $(2 \mathrm{~mL})$. The solution was passed through four connected SepPaks (prewashed with $\mathrm{MeOH}(30 \mathrm{~mL}), \mathrm{MeCN}(30 \mathrm{~mL})$, and water $(70 \mathrm{~mL}))$. The SepPaks were washed with water and eluted with $\mathrm{MeOH}$. The fractions containing product were evaporated, co evaporated with toluene $(5 \mathrm{~mL})$, and dried under vacuum to give $13.9 \mathrm{mg}$ crude product. The crude product was dissolved in pyridine and acetic anhydride $(1: 1,2 \mathrm{~mL})$ and the solution was stirred at room temperature for $21 \mathrm{~h}$. The solvents were co-evaporated with toluene several times to yield $22 \mathrm{mg}$ crude product. Flash chromatography (hexanes/EtOAc 3:4) yielded 11d (10.8 mg, 55\%). ${ }^{1} \mathrm{H}$ NMR (300 MHz, $\mathrm{CDCl}_{3}$ ): $\delta$ $7.64(\mathrm{~d}, 1 \mathrm{H}, J=9.3 \mathrm{~Hz}), 7.37(\mathrm{~d}, 1 \mathrm{H}, J=9.1 \mathrm{~Hz}), 6.85-6.80(\mathrm{~m}, 3 \mathrm{H}), 6.25(\mathrm{~d}, 1 \mathrm{H}, J=9.3 \mathrm{~Hz}), 5.35$ $(\mathrm{d}, 1 \mathrm{H}, J=2.9 \mathrm{~Hz}), 5.21(\mathrm{t}, 1 \mathrm{H}, J=9 \mathrm{~Hz}), 5.14-5.05(\mathrm{~m}, 1 \mathrm{H}), 5.00-4.90(\mathrm{~m}, 2 \mathrm{H}), 4.55-4.40(\mathrm{~m}, 2 \mathrm{H})$, 4.18-4.00 (m, 5H), 3.88 (t, $1 \mathrm{H}, J=7.5 \mathrm{~Hz}), 3.78(\mathrm{t}, 1 \mathrm{H}, J=9.4 \mathrm{~Hz}), 3.65-3.58(\mathrm{~m}, 1 \mathrm{H}), 2.95-2.72$ $(\mathrm{m}, 2 \mathrm{H}), 2.16-2.04(\mathrm{~m}, 23 \mathrm{H}) ;{ }^{13} \mathrm{C}$ NMR $\left(75 \mathrm{MHz}, \mathrm{CDCl}_{3}\right): \delta 170.5,170.4,170.3,170.2,169.9$, $169.8,169.5,169.2,162.2,161.3,156.1,143.5,129.0,113.5,113.0,112.9,101.7,101.3,90.5,84.0$, $77.0,76.3,74.0,71.3,71.0,70.2,69.3,66.9,66.9,62.4,61.1,29.5,27.1,21.1,21.0,20.9,20.9$, 20.8, 20.7; HR-MS (FAB+ of M+, PEG): m/z calcd for $\mathrm{C}_{38} \mathrm{H}_{47} \mathrm{O}_{20} \mathrm{~S}: 8.55 .2381$, found: 855.2360. 


\section{7-(3-(1-thio-2-deoxy-2-acetamido-3,6,2',3',4',6'-O-heptaacetate lactosyl)-propyloxy)coumarin}

(12d) ${ }^{7}$ : UDP-Gal $(17.8 \mathrm{mg}, 29.2 \mu \mathrm{mol})$ was dissolved in an aq. buffer $\left(20 \mathrm{mM}\right.$ in $\mathrm{MnCl}_{2}$ and $0.5 \mathrm{M}$ in sodium cacodylate, $6.5 \mathrm{~mL})$ and $\beta(1-4)$-galactosyltransferase $(500 \mathrm{mU}, 50 \mu \mathrm{L}$ of a $10 \mathrm{U} / \mathrm{mL}$ stock solution in $50 \%$ glycerol) was added, followed by compound 10d (10.0 mg, $22.8 \mu \mathrm{mol})$. The resulting mixture was stirred at room temperature for $6 \mathrm{~h} 20$ min while it slowly became a clear solution. The solution was passed through four connected SepPaks (prewashed with MeOH (20 mL) and water $(50 \mathrm{~mL}))$. The SepPaks were washed with water and eluted with $\mathrm{MeOH}$. The fractions containing product were lyophilized to give $15.9 \mathrm{mg}$ crude product. The crude product was dissolved in pyridine and acetic anhydride $(1: 1,2 \mathrm{~mL})$ to give a slurry and the mixture was stirred at room temperature for $22 \mathrm{~h}$. After $20 \mathrm{~min}$, the mixture had turned into a solution. The solution was co-evaporated with toluene $(3 \mathrm{x} 50 \mathrm{~mL})$ to give $30 \mathrm{mg}$ crude product. Flash chromatography (hexanes/EtOAc 1:2-0:1 - dichloromethane/MeOH 4:1-1:1 and EtOAc) yielded 12d (12.5 mg, 64\%). ${ }^{1} \mathrm{H}$ NMR $\left(300 \mathrm{MHz}, \mathrm{CDCl}_{3}\right): \delta 7.65(\mathrm{~d}, 1 \mathrm{H}, J=9.5 \mathrm{~Hz}), 7.37(\mathrm{~d}, 1 \mathrm{H}, J=9.1 \mathrm{~Hz}), 6.87-6.78$ $(\mathrm{m}, 2 \mathrm{H}), 6.26(\mathrm{~d}, 1 \mathrm{H}, J=9.5 \mathrm{~Hz}), 5.63(\mathrm{~d}, 1 \mathrm{H}, J=9.6 \mathrm{~Hz}), 5.36(\mathrm{br} \mathrm{s}, 1 \mathrm{H}), 5.16-5.02(\mathrm{~m}, 2 \mathrm{H}), 4.97$ $(\mathrm{dd}, 1 \mathrm{H}, J=10.4 \mathrm{~Hz}, 3.1 \mathrm{~Hz}), 4.55-4.42(\mathrm{~m}, 2 \mathrm{H}), 4.23-4.02(\mathrm{~m}, 7 \mathrm{H}), 3.89(\mathrm{t}, 1 \mathrm{H}, J=6.5 \mathrm{~Hz}), 3.79$ $(\mathrm{t}, 1 \mathrm{H}, J=9.2 \mathrm{~Hz}), 3.64-3.55(\mathrm{~m}, 1 \mathrm{H}), 2.99-2.76(\mathrm{~m}, 2 \mathrm{H}), 2.23-1.92(\mathrm{~m}, 23 \mathrm{H}) ;{ }^{13} \mathrm{C} \mathrm{NMR}(75 \mathrm{MHz}$, $\left.\mathrm{CDCl}_{3}\right): \delta 171.0,170.4,170.3,170.2,170.1,169.3,162.0,161.2,155.8,143.4,128.8,113.1,112.9$ 101.4, 101.1, 85.0, 77.4, 77.0, 76.7, 76.6, 76.1, 74.1, 70.8, 70.7, 69.1, 66.6, 62.2, 60.7, 52.8, 29.1, 26.8, 23.2, 20.8, 20.6, 20.5; HR-MS (FAB+ of M+, PEG): m/z calcd for $\mathrm{C}_{38} \mathrm{H}_{48} \mathrm{NO}_{19} \mathrm{~S}: 854.2541$, found: 854.2525 . 
General procedure for the glycosylations using lactose 11d. The donor and acceptor were dried by co-evaporation with toluene $(3 \times 5 \mathrm{~mL})$ and then kept under vacuum for $2 \mathrm{~h}$. A solution of alcohol (1 equivalent), thioglycoside donor (1.2 equivalents) and powdered molecular sieves (4 Å, 50-100 mg) in anhdrous dichloromethane $(5-10 \mathrm{~mL})$ was cooled to $0{ }^{\circ} \mathrm{C}$ before $\mathrm{N}$-iodosuccinimide (3 equiv.) and silver triflate (0.3 equiv.) were added. After stirring for $15-20$ min at $0{ }^{\circ} \mathrm{C}, \mathrm{Et}_{3} \mathrm{~N}$ $(0.05 \mathrm{~mL})$ was added and the reaction mixture was then diluted with dichloromethane $(10 \mathrm{~mL})$ and filtered through Celite. The filtrate was washed successively with a saturated aqueous solution of $\mathrm{Na}_{2} \mathrm{~S}_{2} \mathrm{O}_{3}$, water and brine. After drying $\left(\mathrm{Na}_{2} \mathrm{SO}_{4}\right)$, the organic phase was filtered and concentrated and the residue was purified by chromatography (hexanes/EtOAc, 1:1->1:2).

Spectral data of compounds $\mathbf{1 3}^{8}$ and $14^{9}$ were in accordance with previous reports.

Compound 15: ${ }^{1} \mathrm{H}$ NMR $\left(300 \mathrm{MHz}, \mathrm{CDCl}_{3}\right): \delta$ 7.42-7.25 (m, 10H), $5.62(\mathrm{~d}, 1 \mathrm{H}, J=7.8 \mathrm{~Hz}), 5.35$ $(\mathrm{d}, 1 \mathrm{H}, J=2.9 \mathrm{~Hz}), 5.21-5.05(\mathrm{~m}, 7 \mathrm{H}), 4.95(\mathrm{dd}, 1 \mathrm{H}, J=10.4,3.3 \mathrm{~Hz}), 4.84(\mathrm{t}, 1 \mathrm{H}, J=8.7 \mathrm{~Hz})$, 4.55-4.35 (m, 4H), $4.25(\mathrm{dd}, 1 \mathrm{H}, J=10.7,2.6 \mathrm{~Hz}), 4.17-4.00(\mathrm{~m}, 4 \mathrm{H}), 3.92-3.82(\mathrm{~m}, 2 \mathrm{H}), 3.74(\mathrm{t}$, $1 \mathrm{H}, J=9.4 \mathrm{~Hz}), 3.52-3.40(\mathrm{~m}, 1 \mathrm{H}), 2.16\left(\right.$ br s, 3H), 2.12-1.93 (m, 18H); ${ }^{13} \mathrm{C}$ NMR $(75 \mathrm{MHz}$, $\left.\mathrm{CDCl}_{3}\right): \delta 177.5,170.3,170.1,170.0,169.7,169.6,169.4,169.0,155.8,136.1,135.8,128.7,128.6$, $128.2,101.1,100.9,72.7,72.6,71.4,71.0,70.7,69.4,69.1,67.6,67.2,66.6,61.9,60.9,54.5,29.7$, 29.6, 20.8-20.5 (7 carbons); HR-MS (FAB+ of $\mathrm{M}+, \mathrm{PEG}): \mathrm{m} / \mathrm{z}$ calcd for $\mathrm{C}_{44} \mathrm{H}_{53} \mathrm{NO}_{22}$ : 947.3059 , found: 947.3093 . 


\section{References}

1. D. A. Fulton, J. F. Stoddart, J. Org. Chem. 2001, 66 (25), 8309-8319.

2. D. Horton, M. L. Wolfrom, J. Org. Chem. 1962, 27 (5), 1794-1800.

3. S. H. Reich, M. Melnick, M. J. Pino, M. A. M. Fuhry, A. J. Trippe, K. Appelt, J. F. Davies II, B-

W. Wu, L. Musick, J. Med. Chem. 1996, 39 (14), 2781-2794.

4. P. J. Jerris, A. B. Smith III, J. Org. Chem. 1981, 46 (3), 577-585.

5. C. D. Hurd, L. Scherling, J. Am. Chem. Soc. 1937, 59 (1), 112-117.

6. C-H. Wong, Y. Ichikawa, T. Krach, C. Gautheron-Le Narvor, D. P. Dumas, G. C. Look, J. Am.

Chem. Soc. 1991, 113 (21), 8137-8145.

7. O. Blixt, T. Norberg, Carbohydr. Res. 1999, 319, 80-91.

8. H. Kondo, S. Aoki, Y. Ichikawa, R. L. Halcomb, H. Ritzen, C-H. Wong, J. Org. Chem. 1994, 59 (4), 864-77.

9. W. B. Turnbull, J. A. Harrison, K. P. Ravindranathan, S. Schenkman, R. A. Field, Tetrahedron 2002, 58 (16), 3207-3216. 

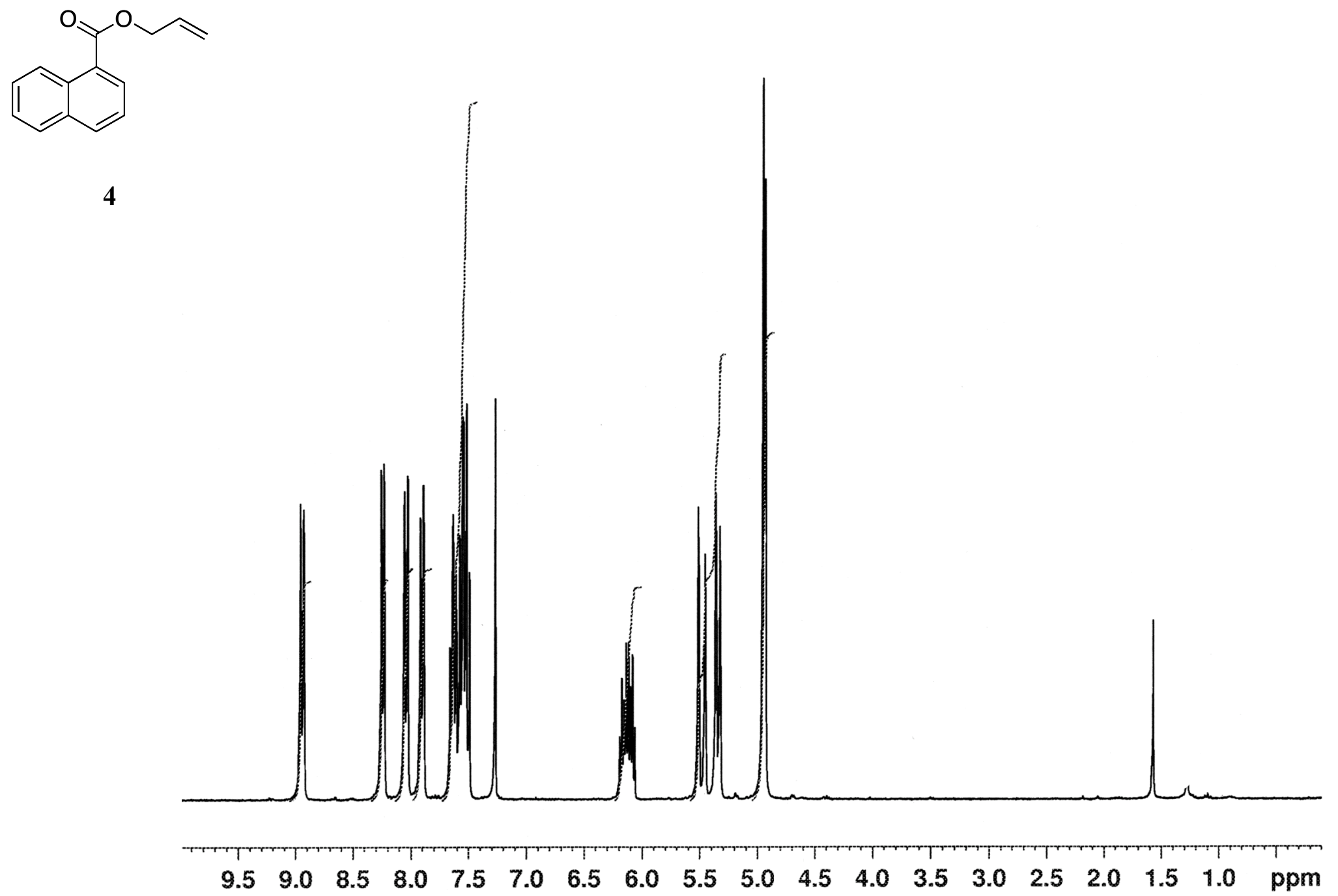


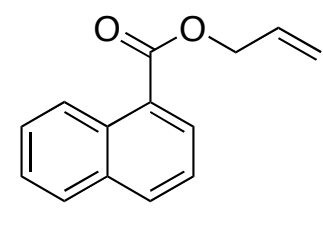

4

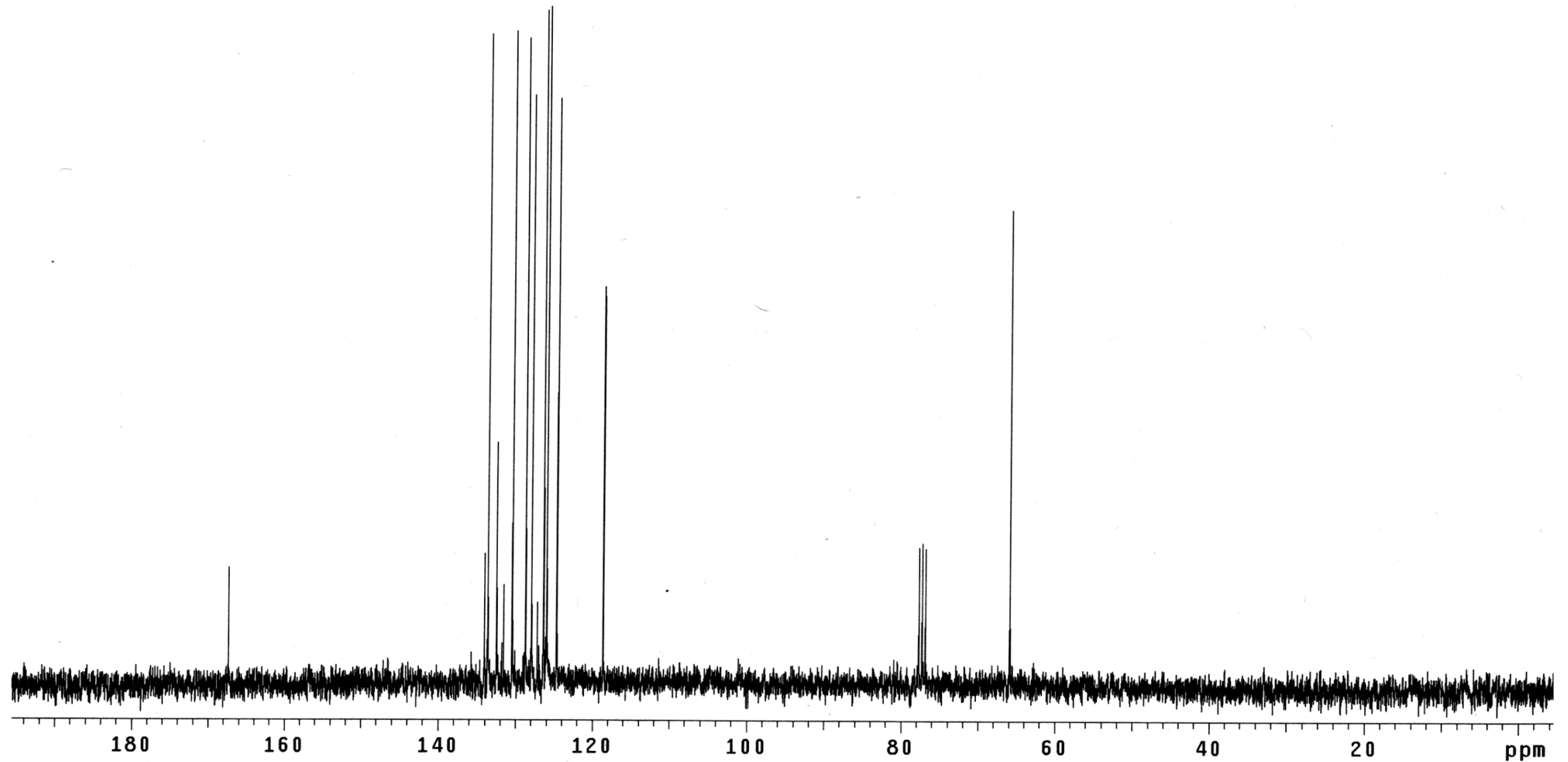


S 15

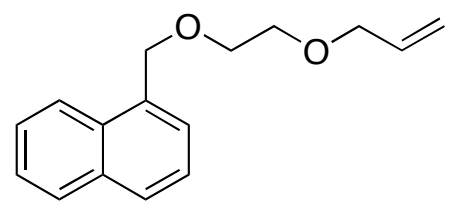

5

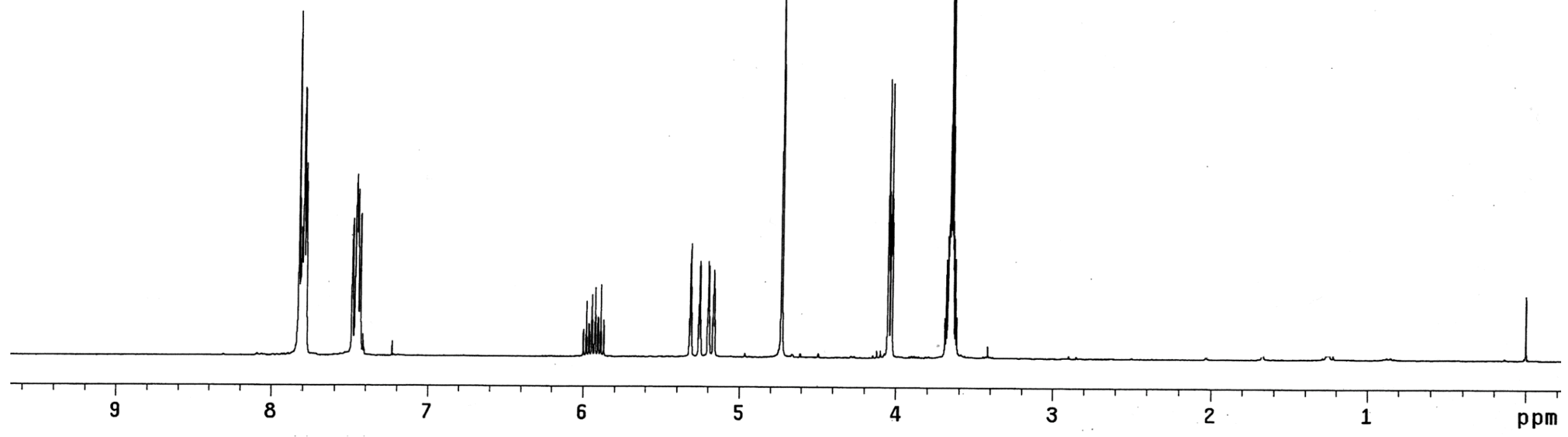




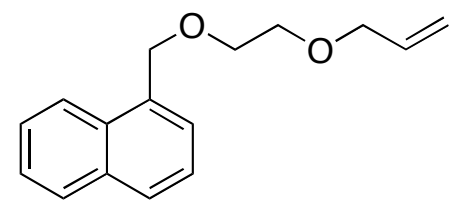

5

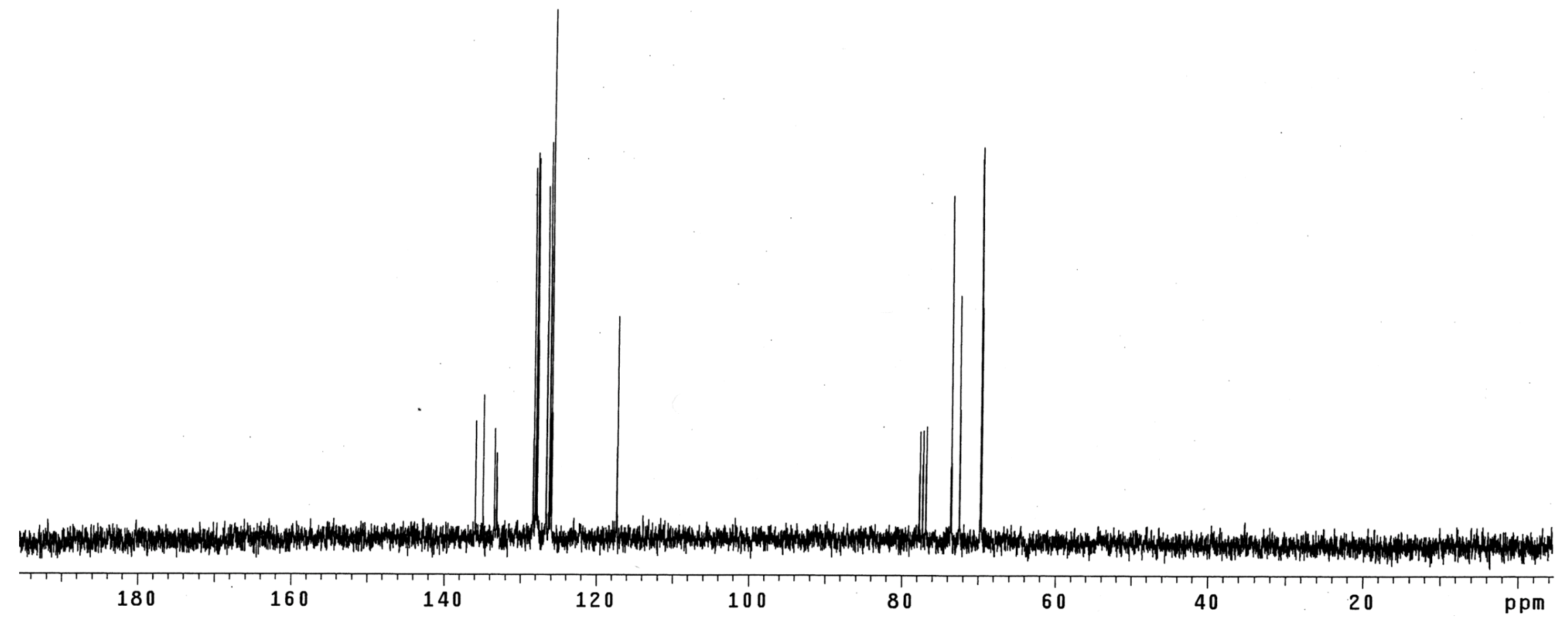



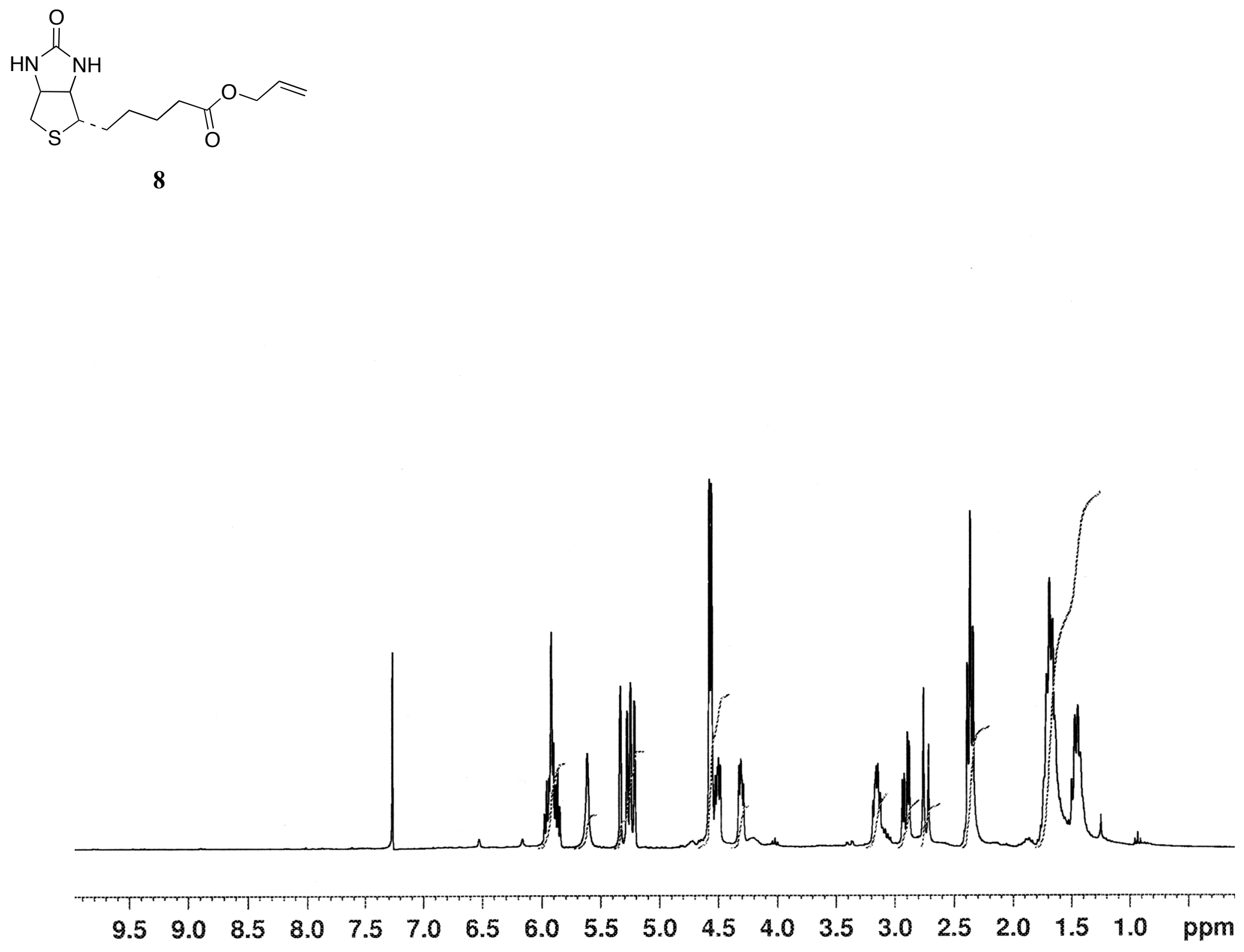


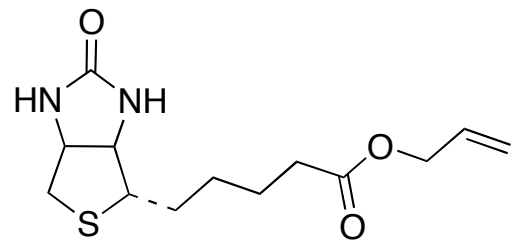

8

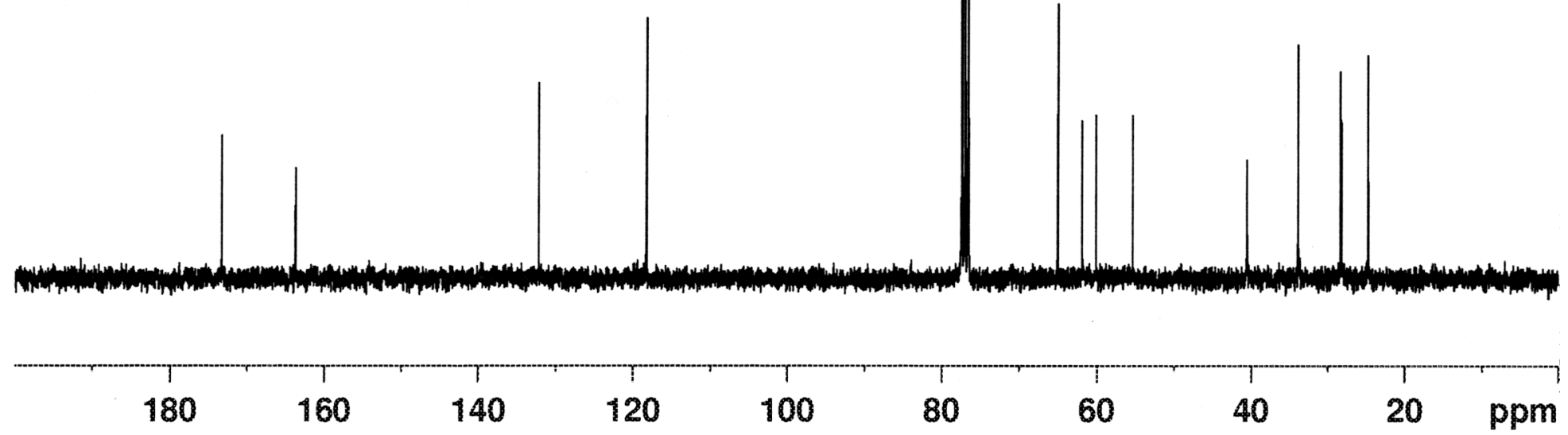


S 19
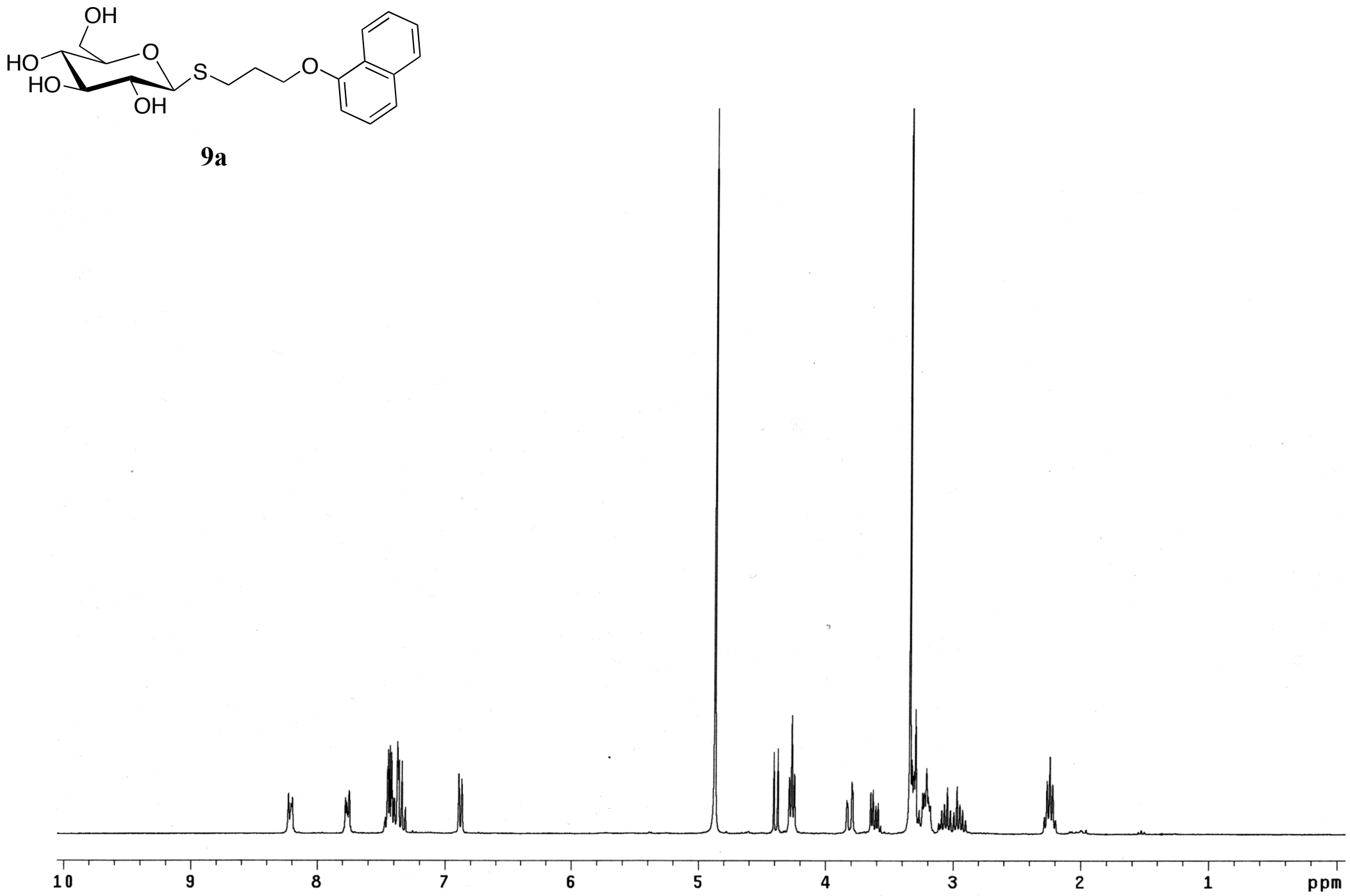


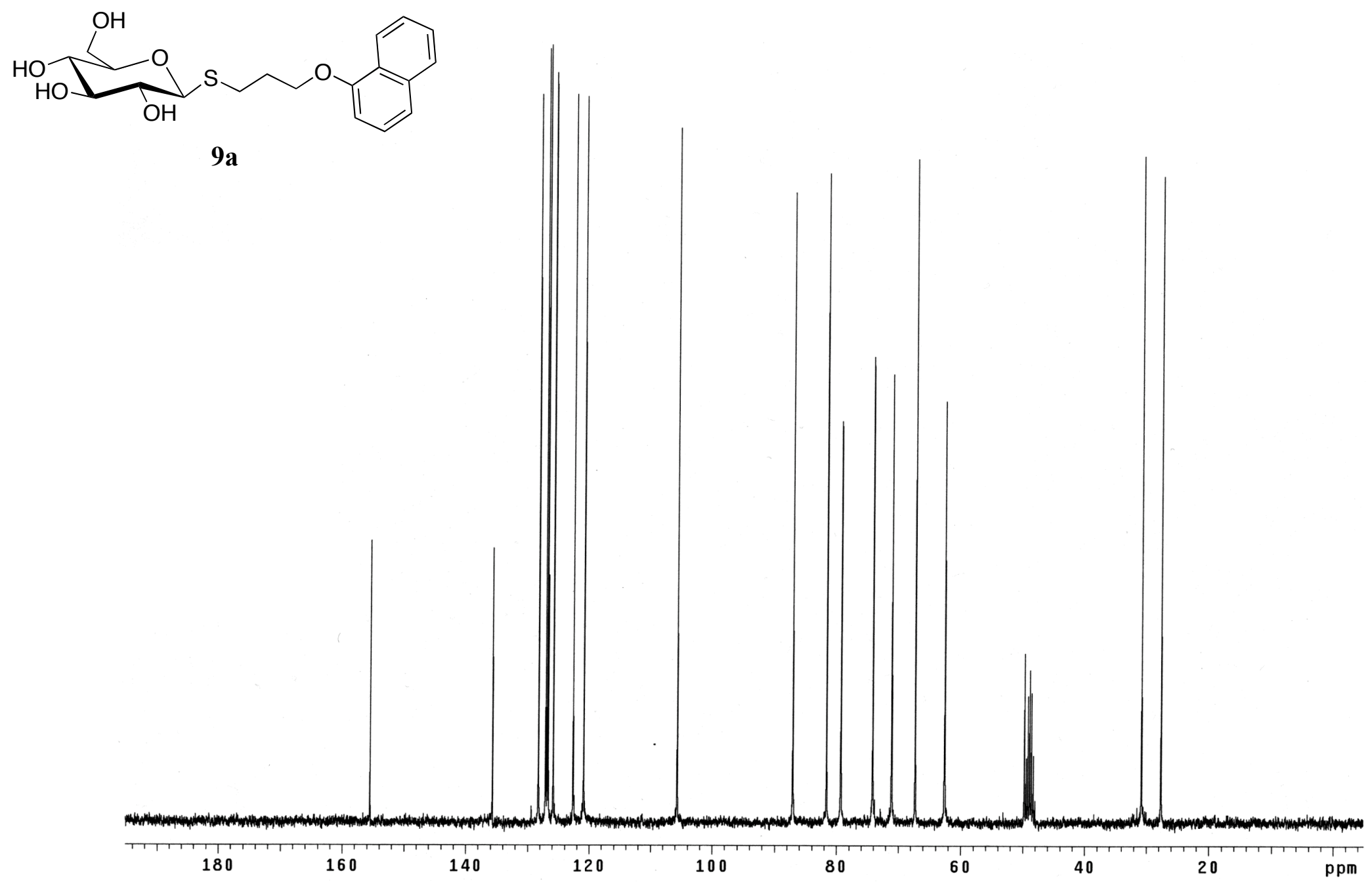


S 21

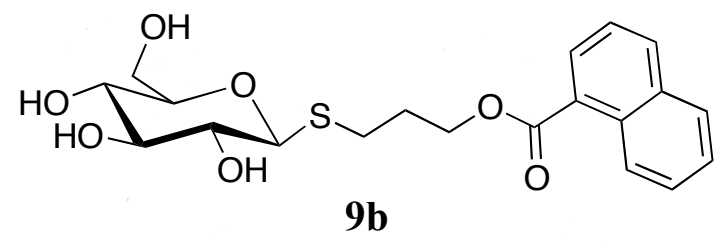




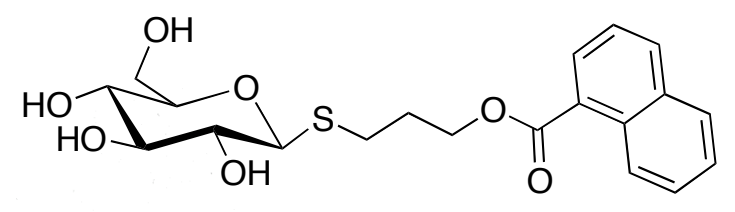

9b

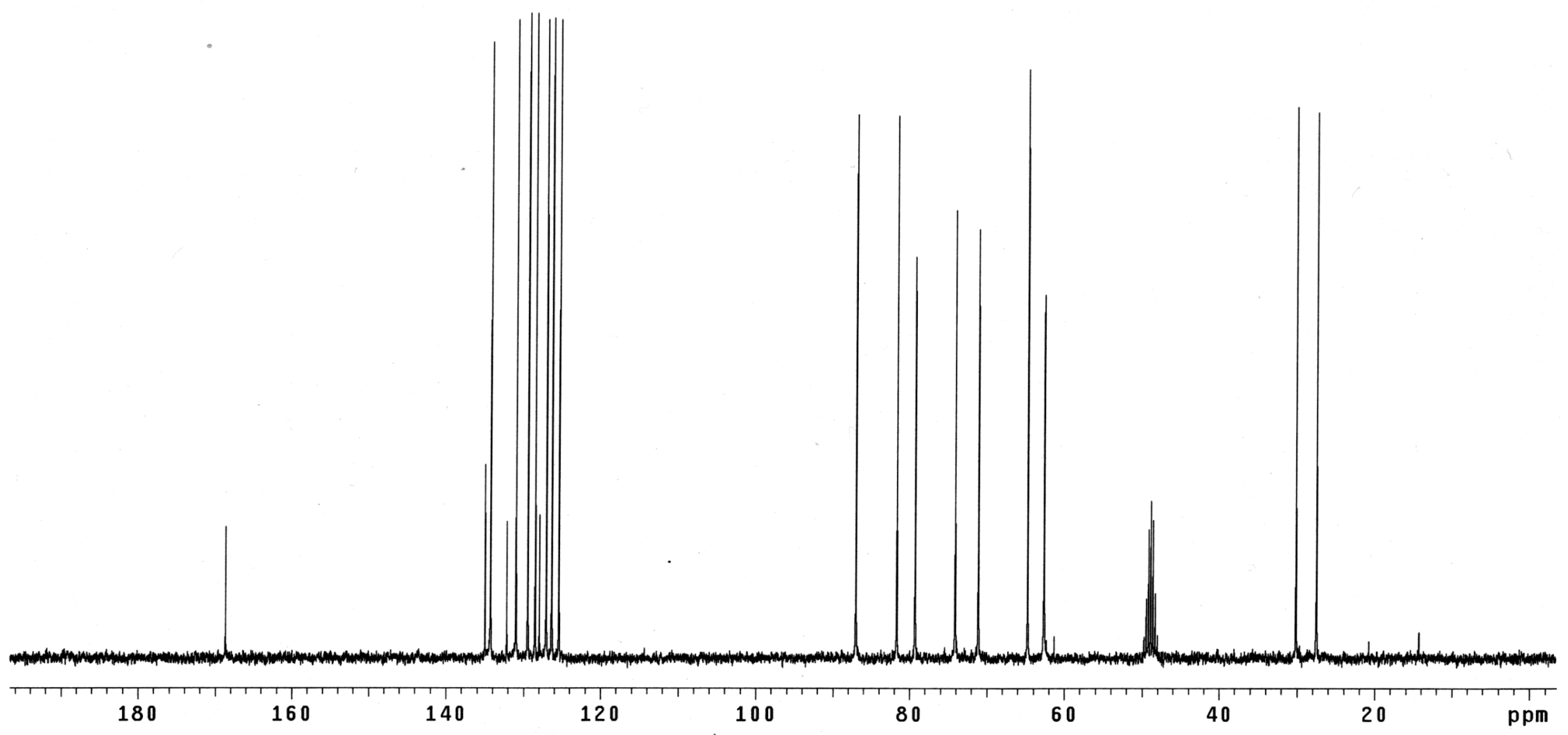


$\underbrace{\mathrm{OH}}_{\mathrm{OH}}$

9c

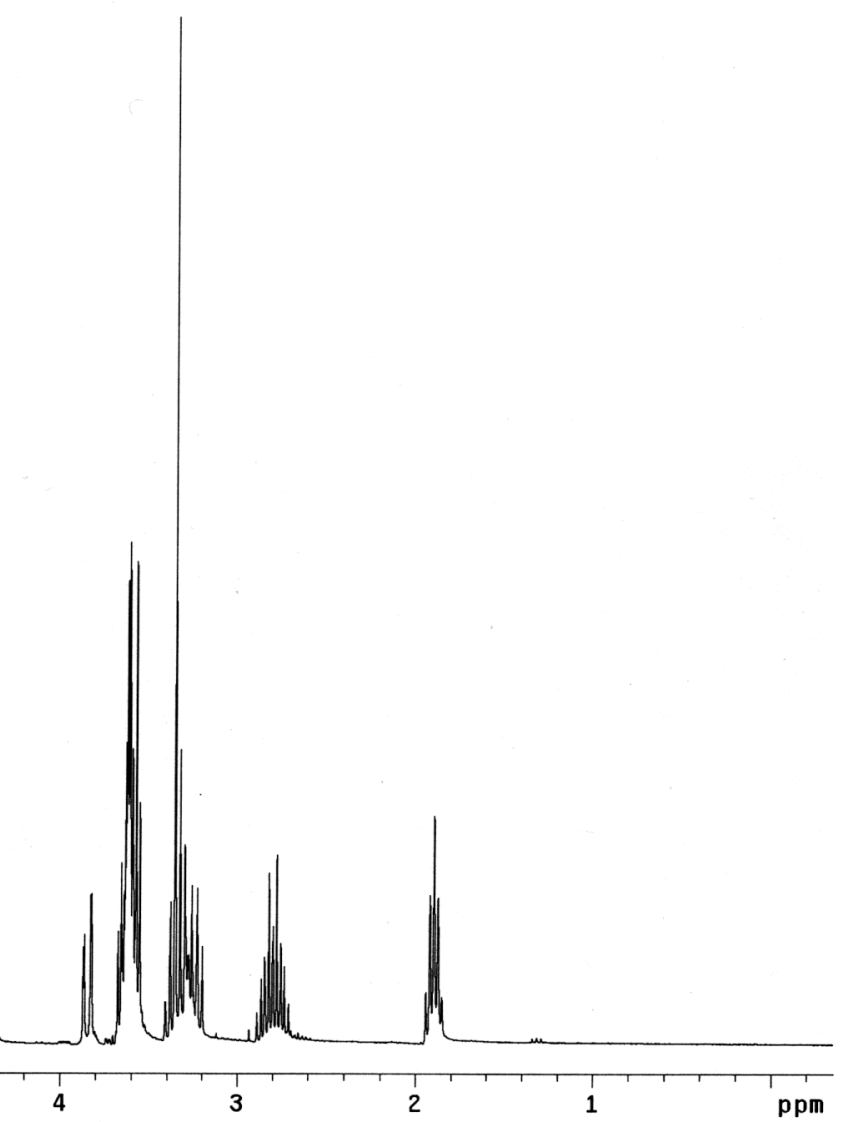




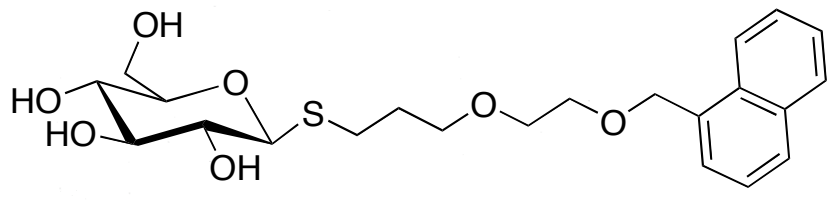

$9 c$

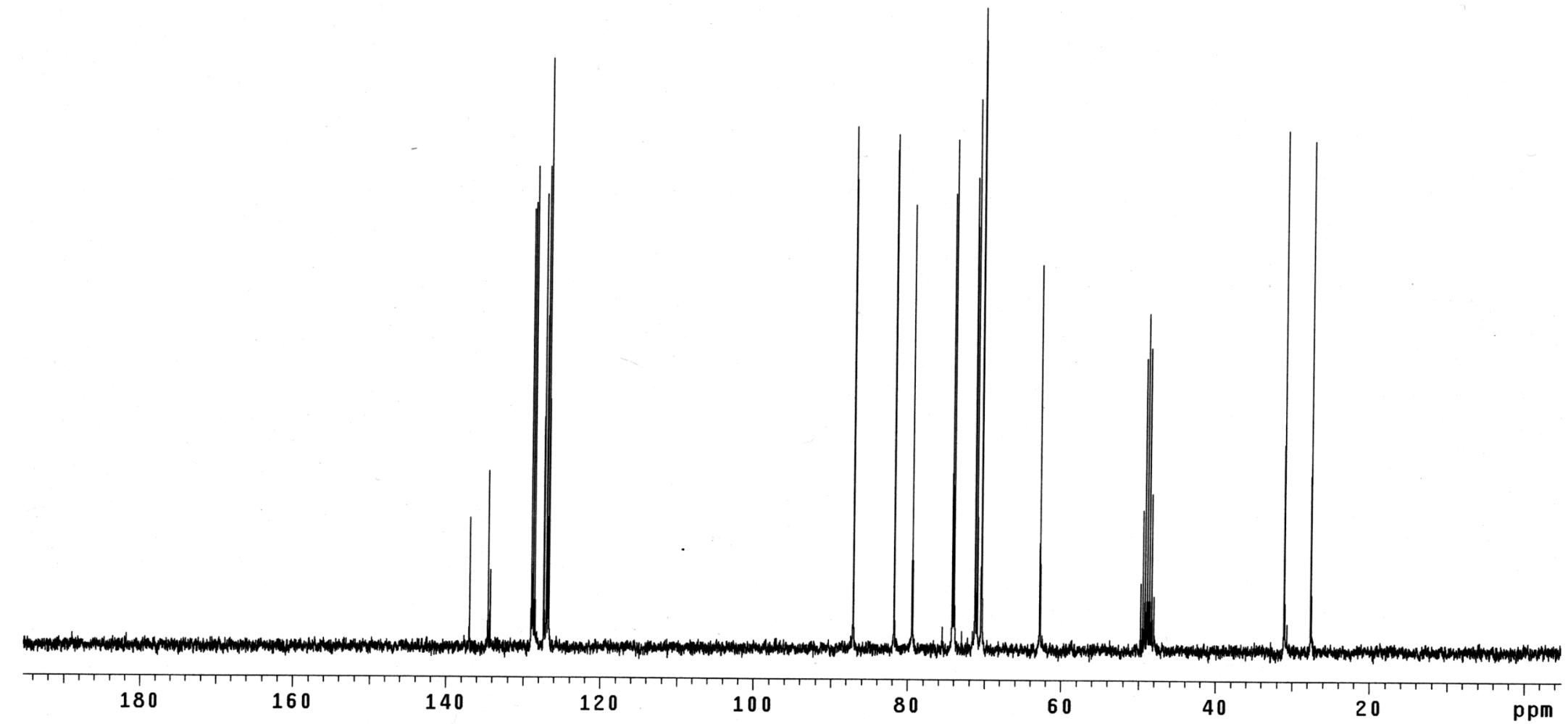




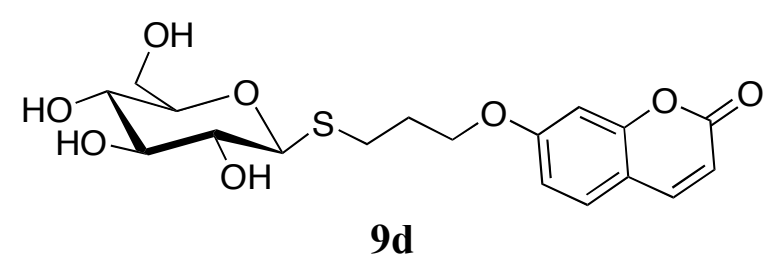




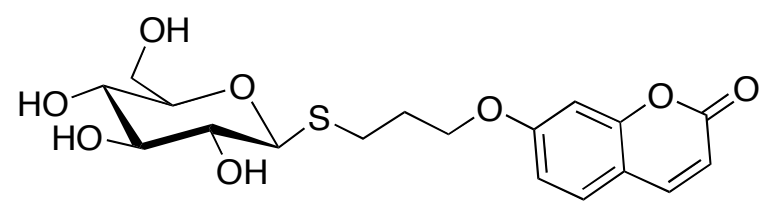

9d

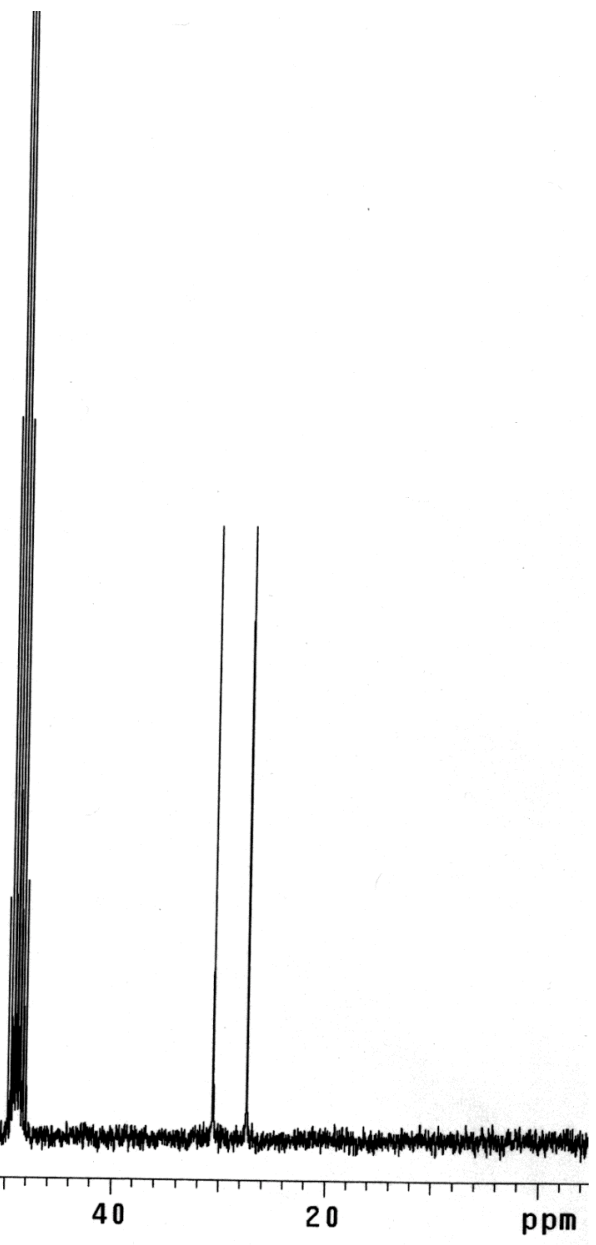



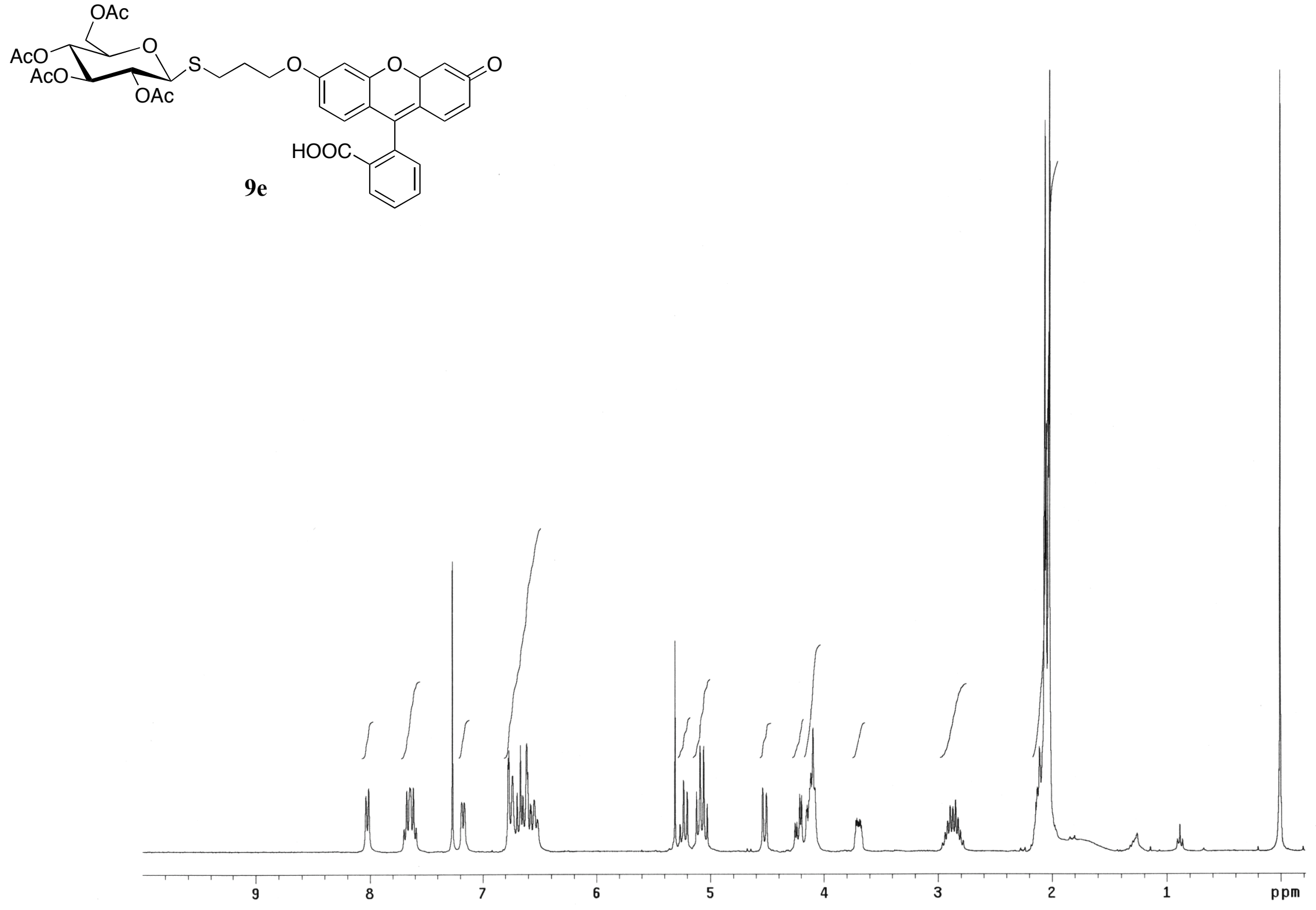

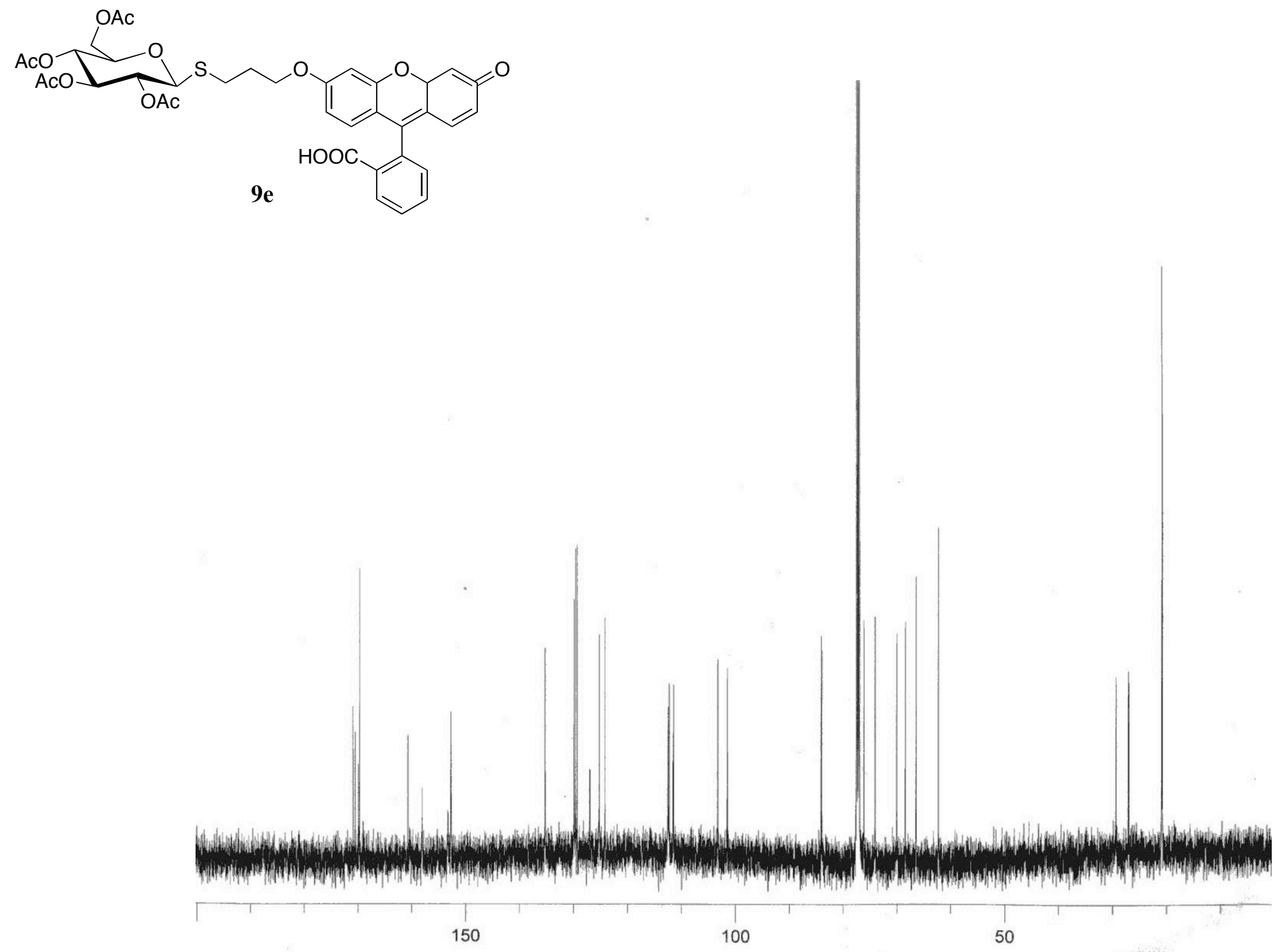

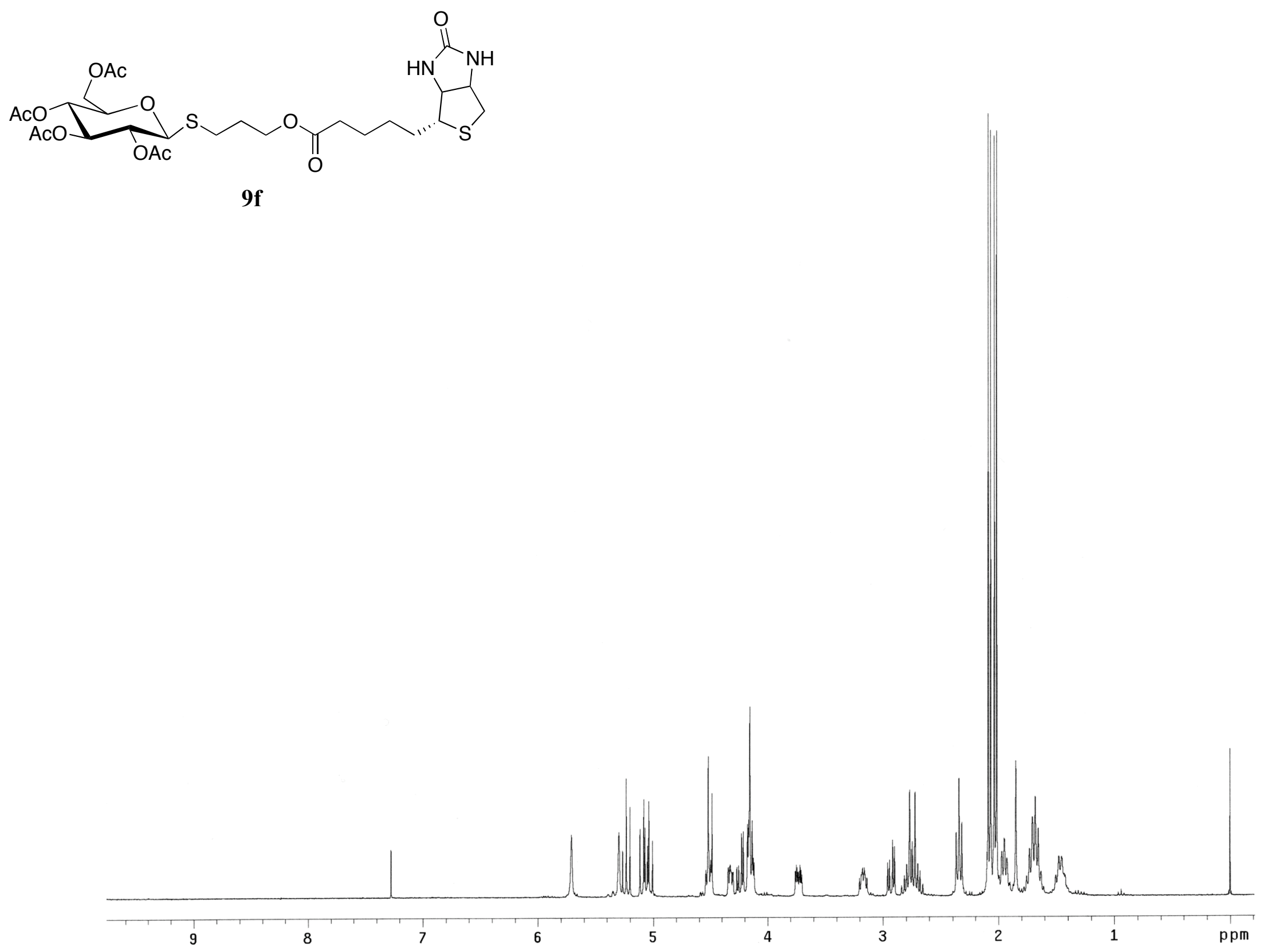


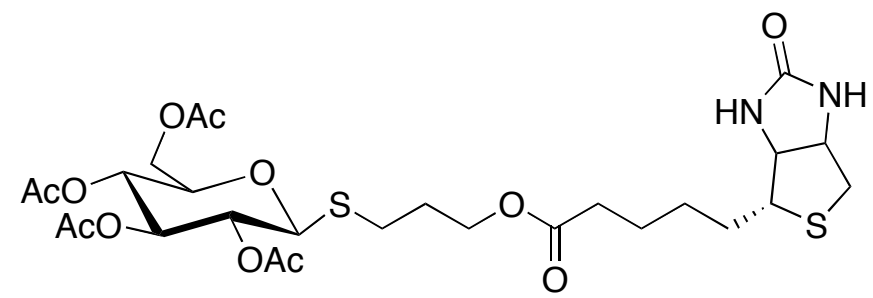

9f

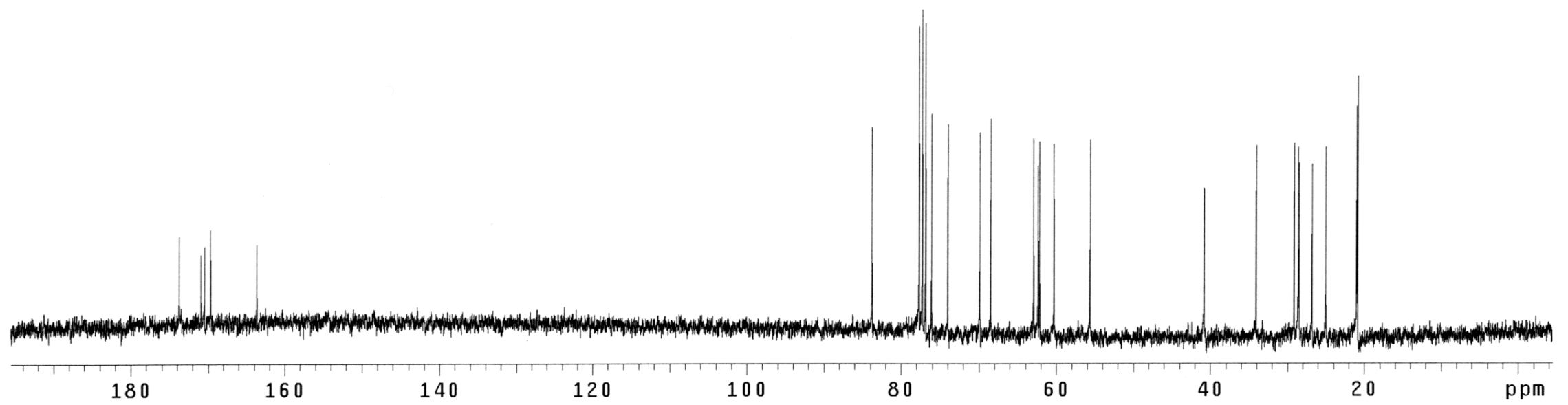



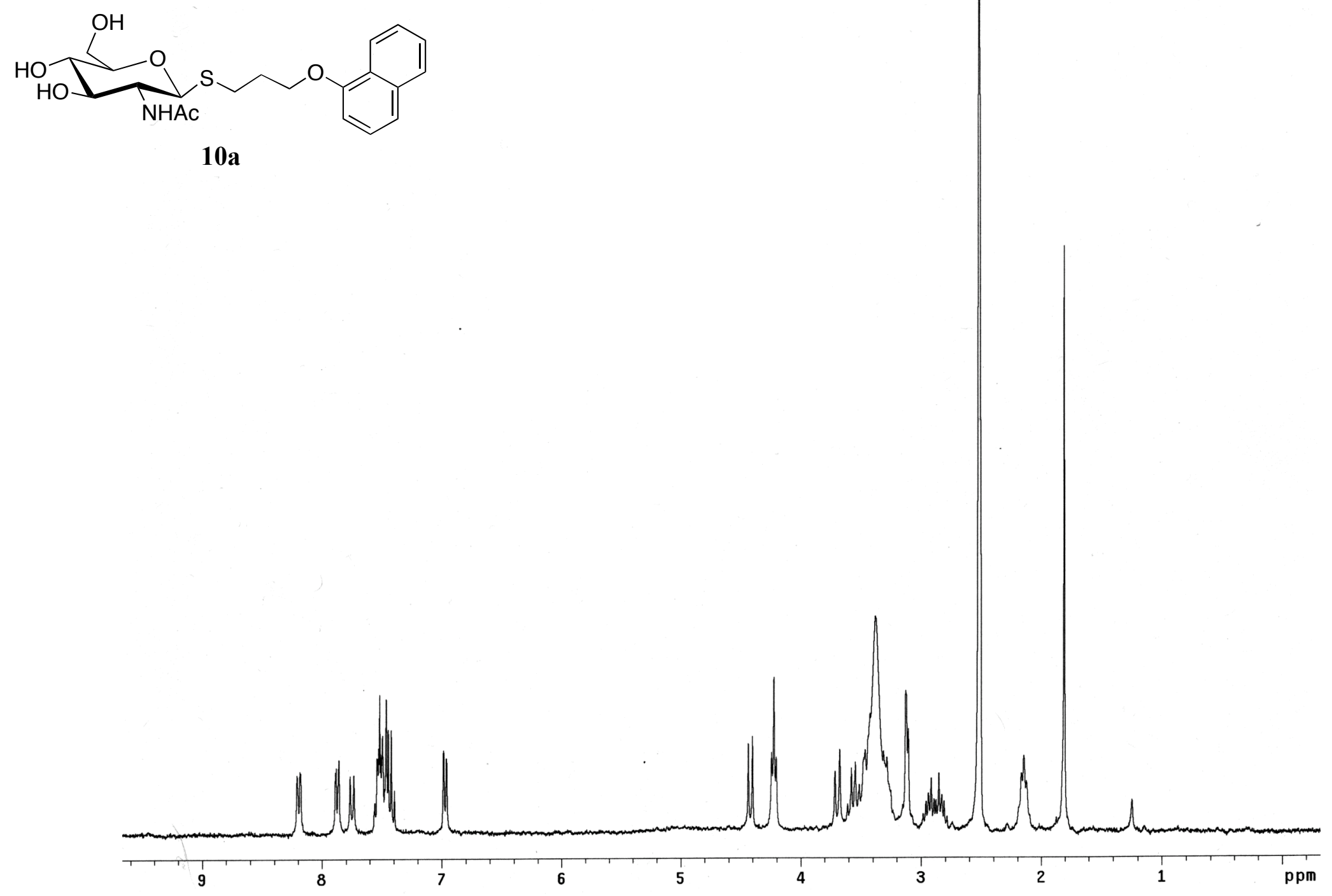

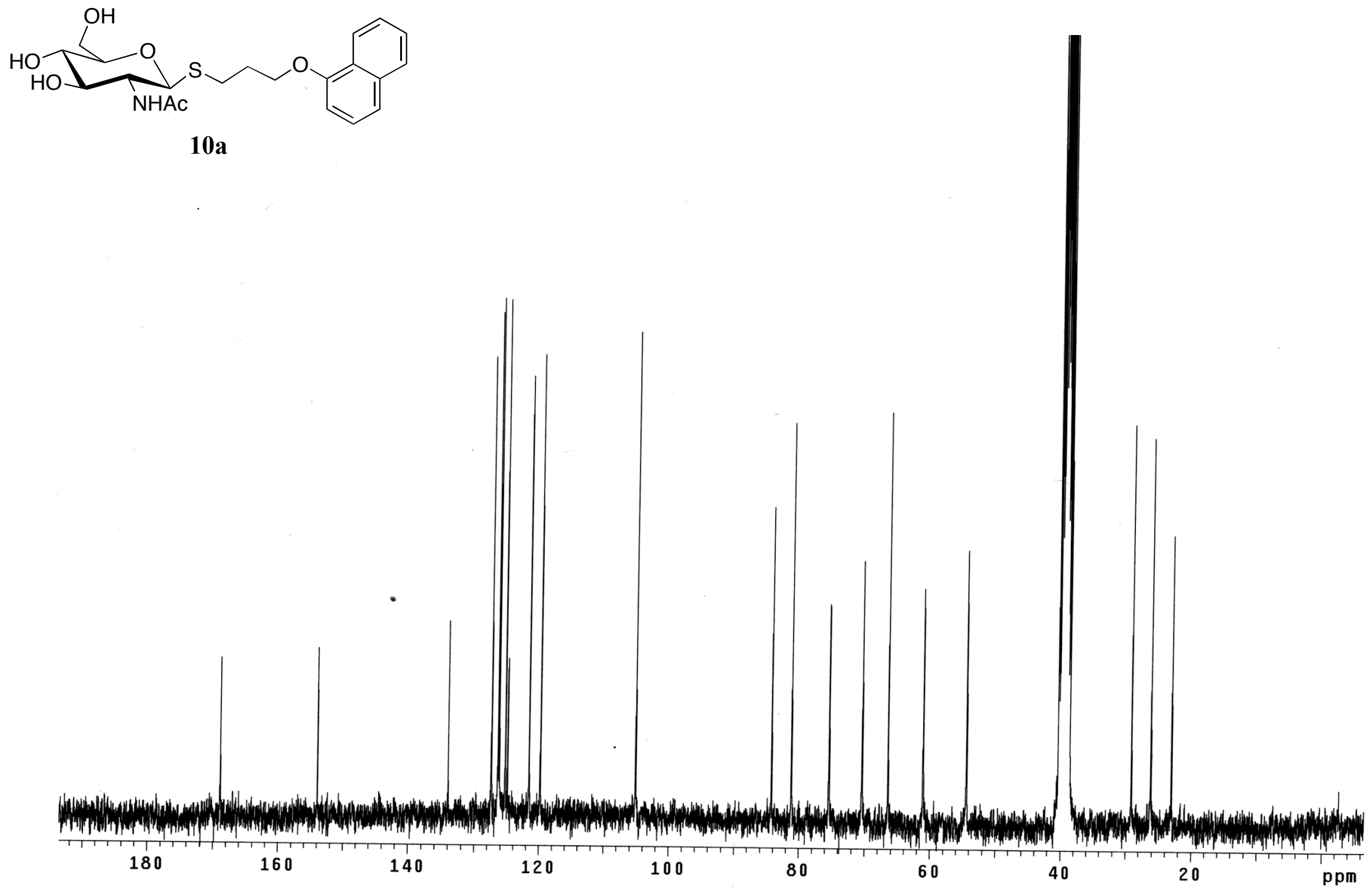
S 33

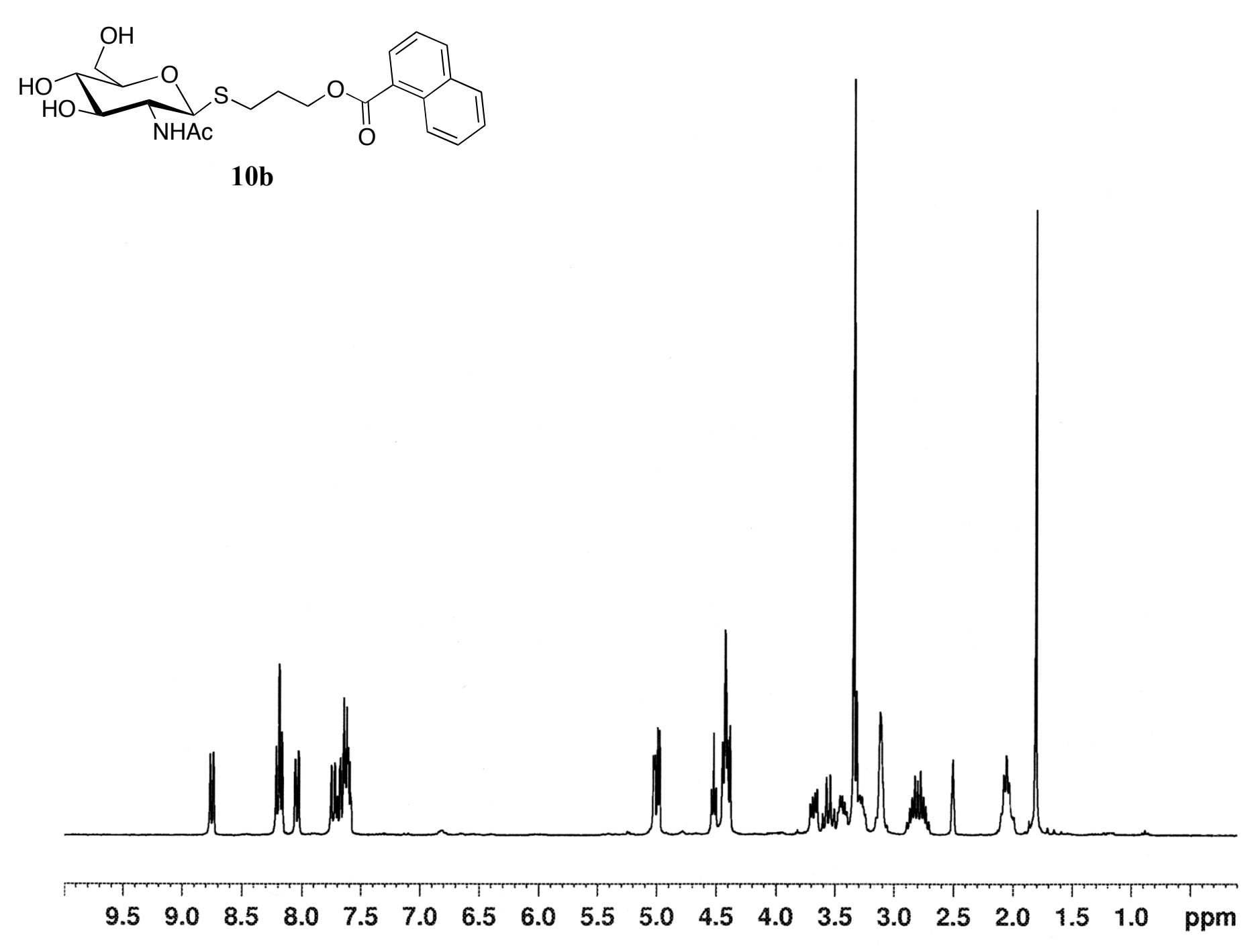




$$
\perp
$$



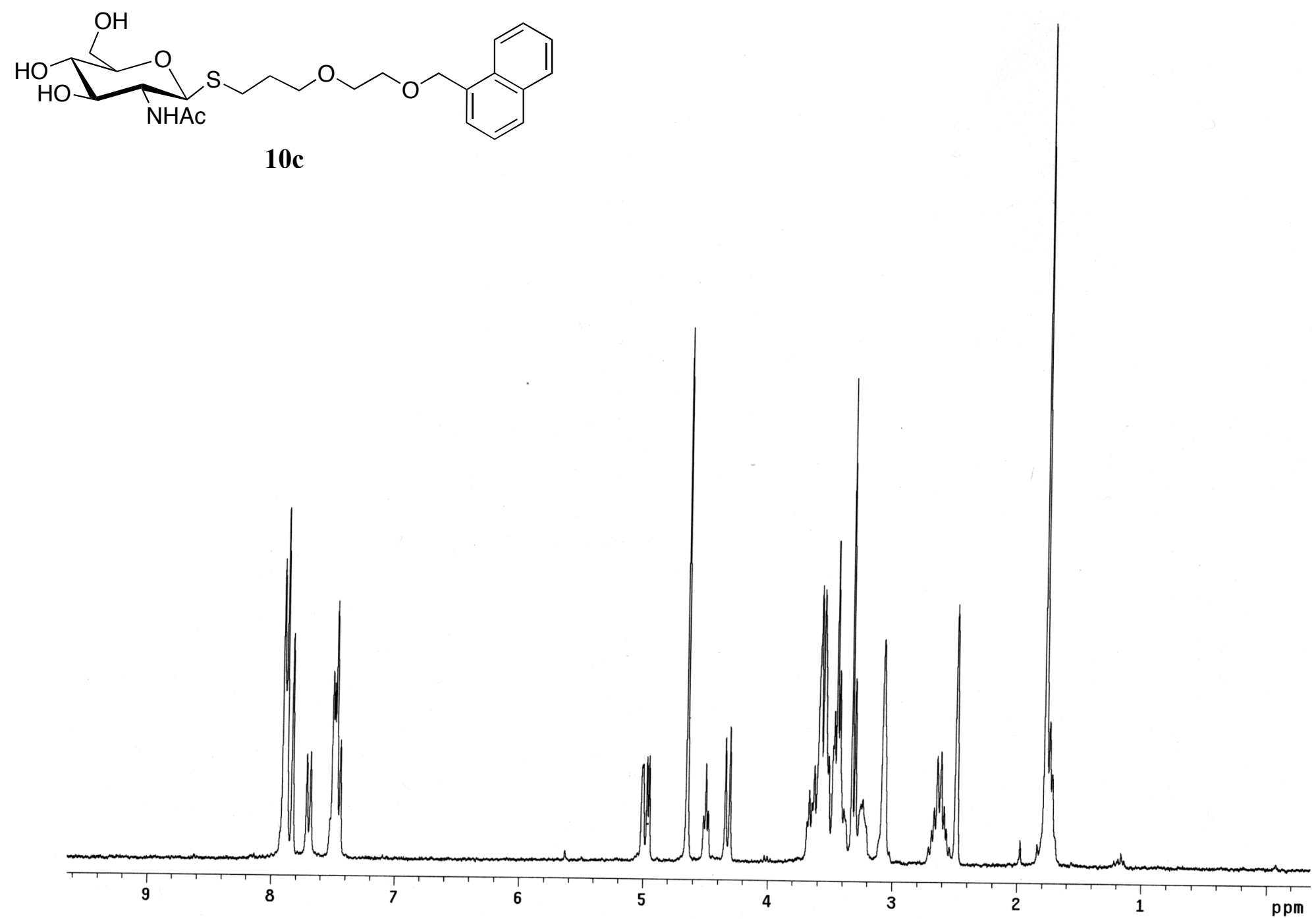

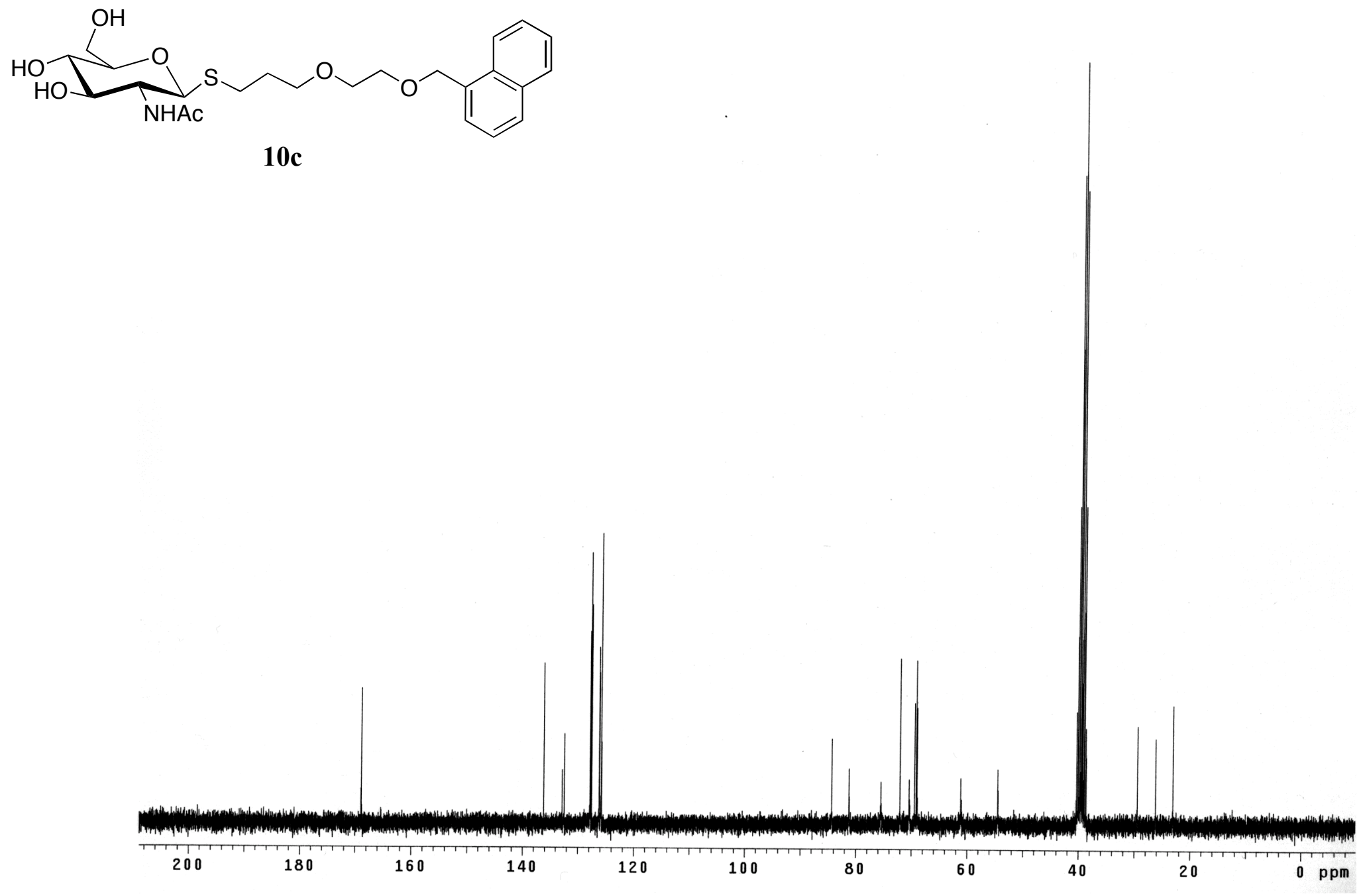

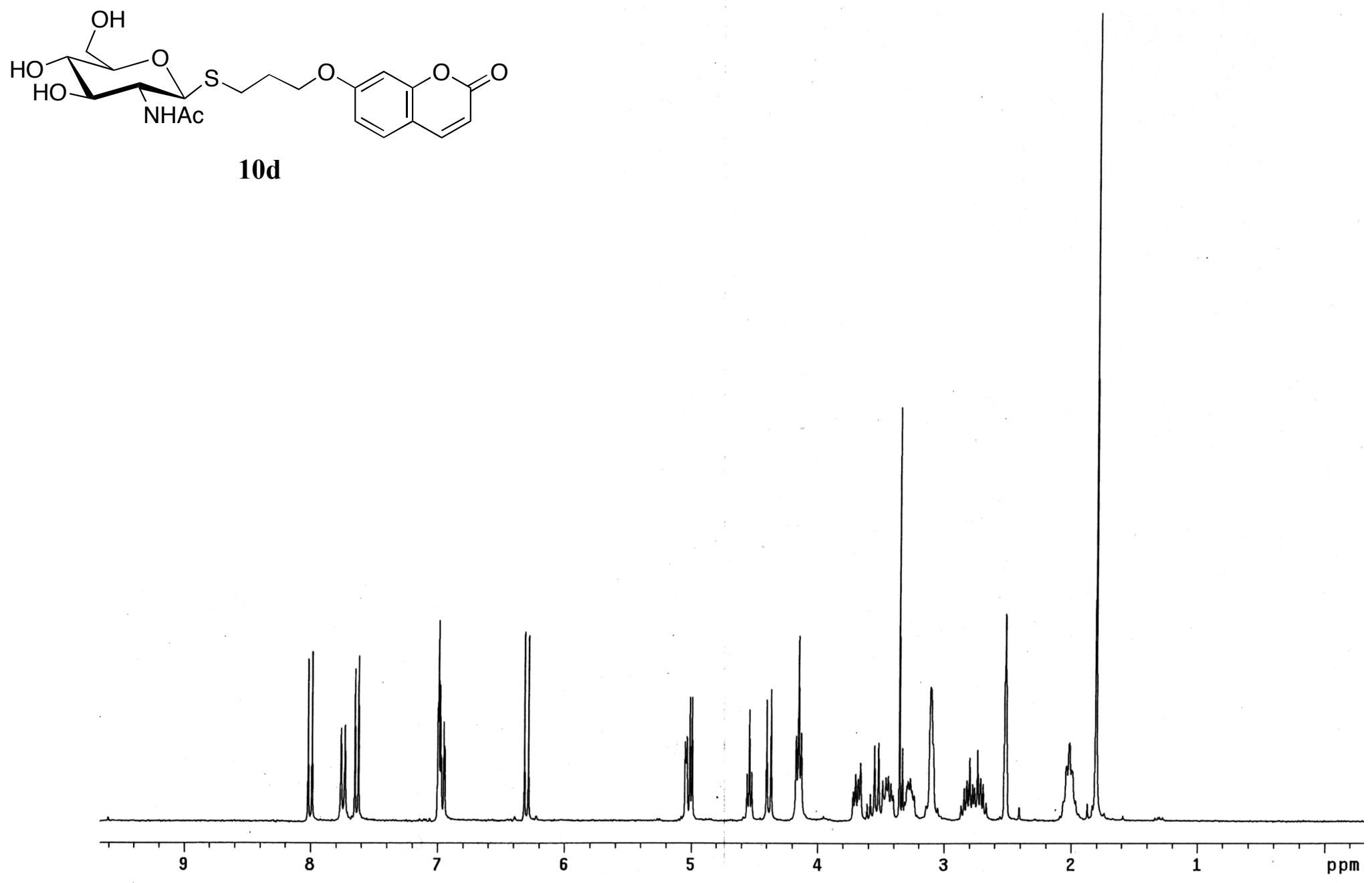

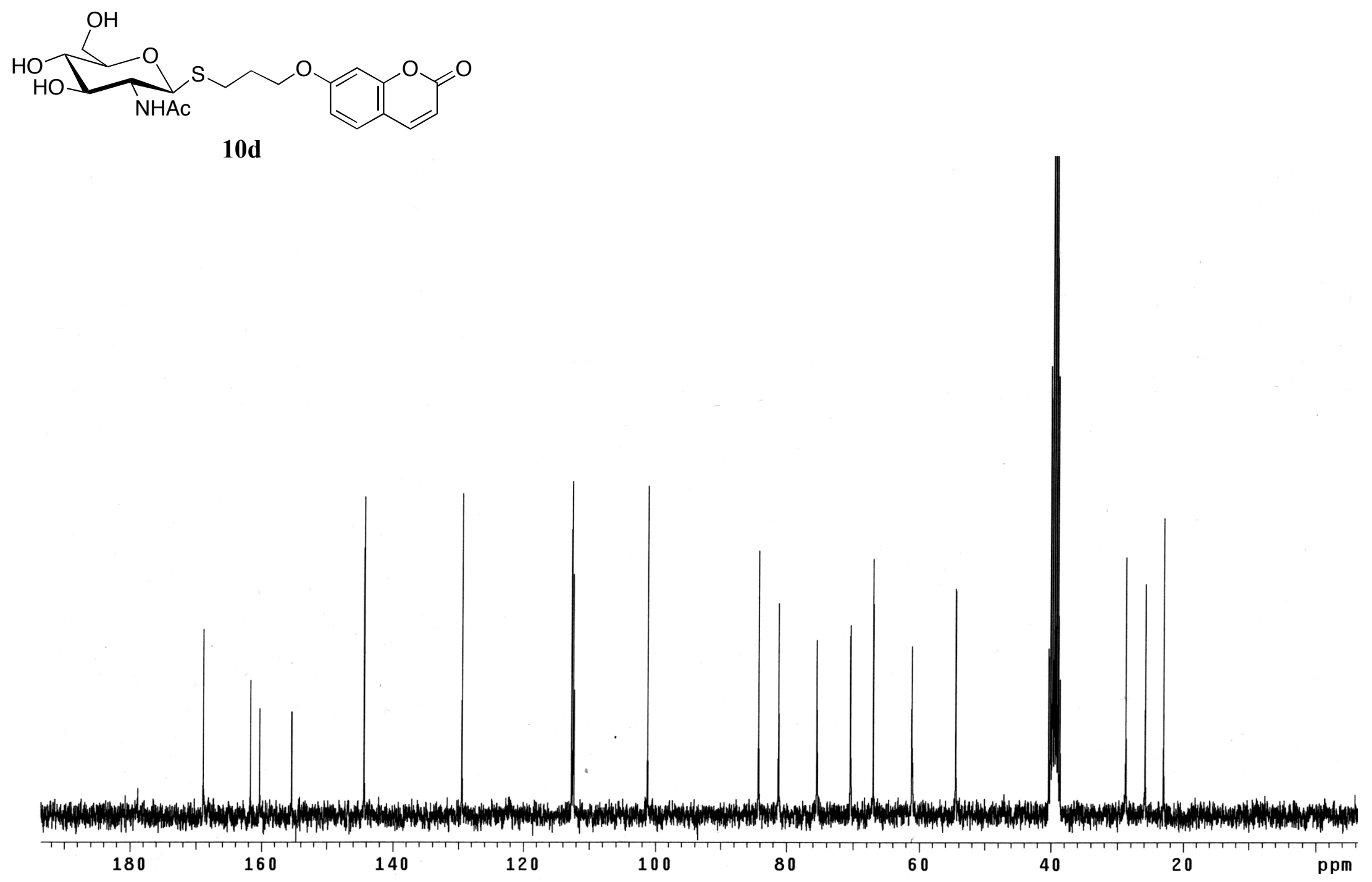

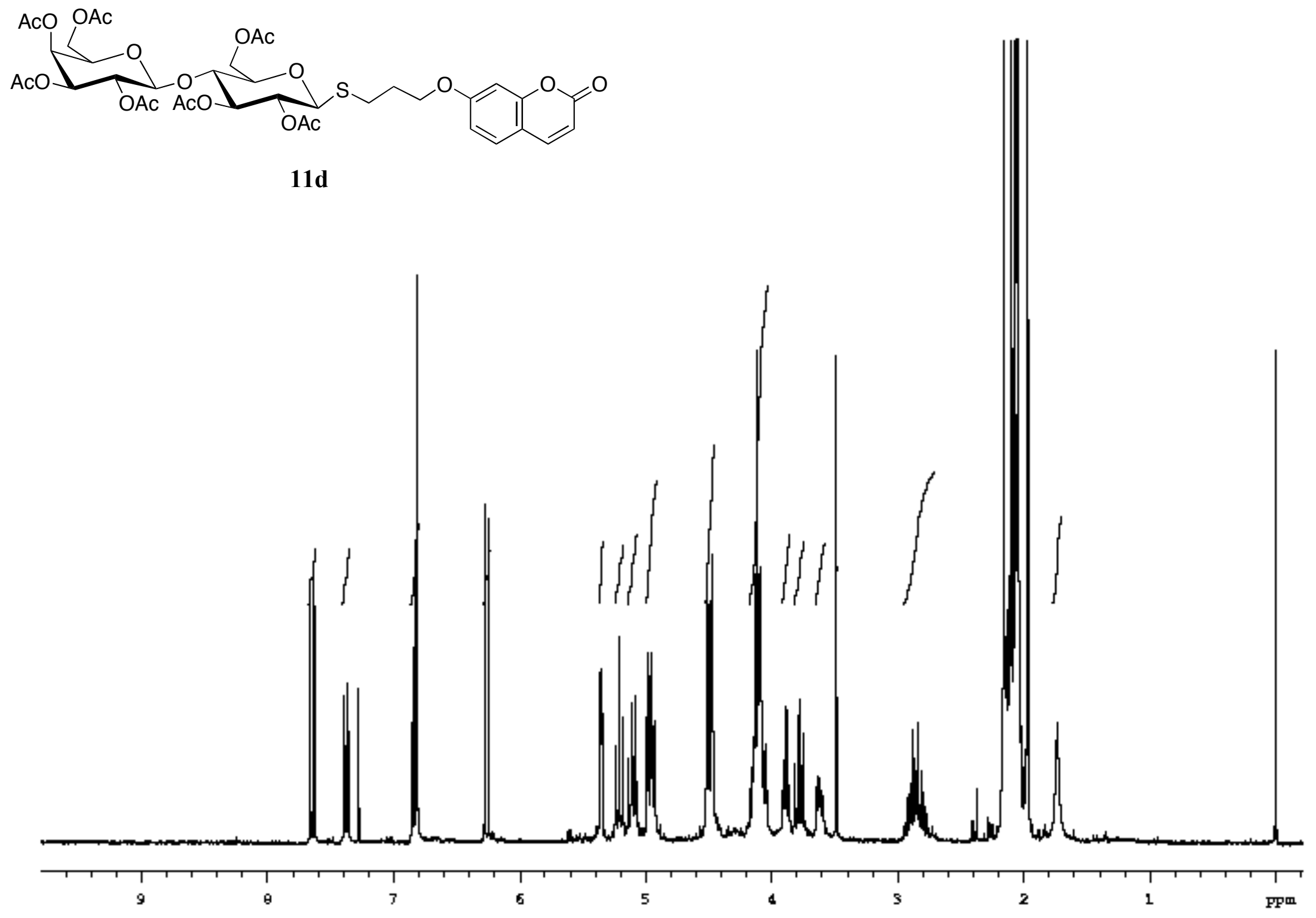


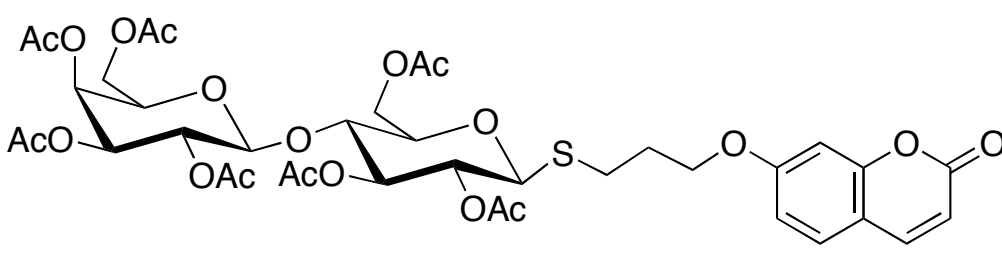

11d

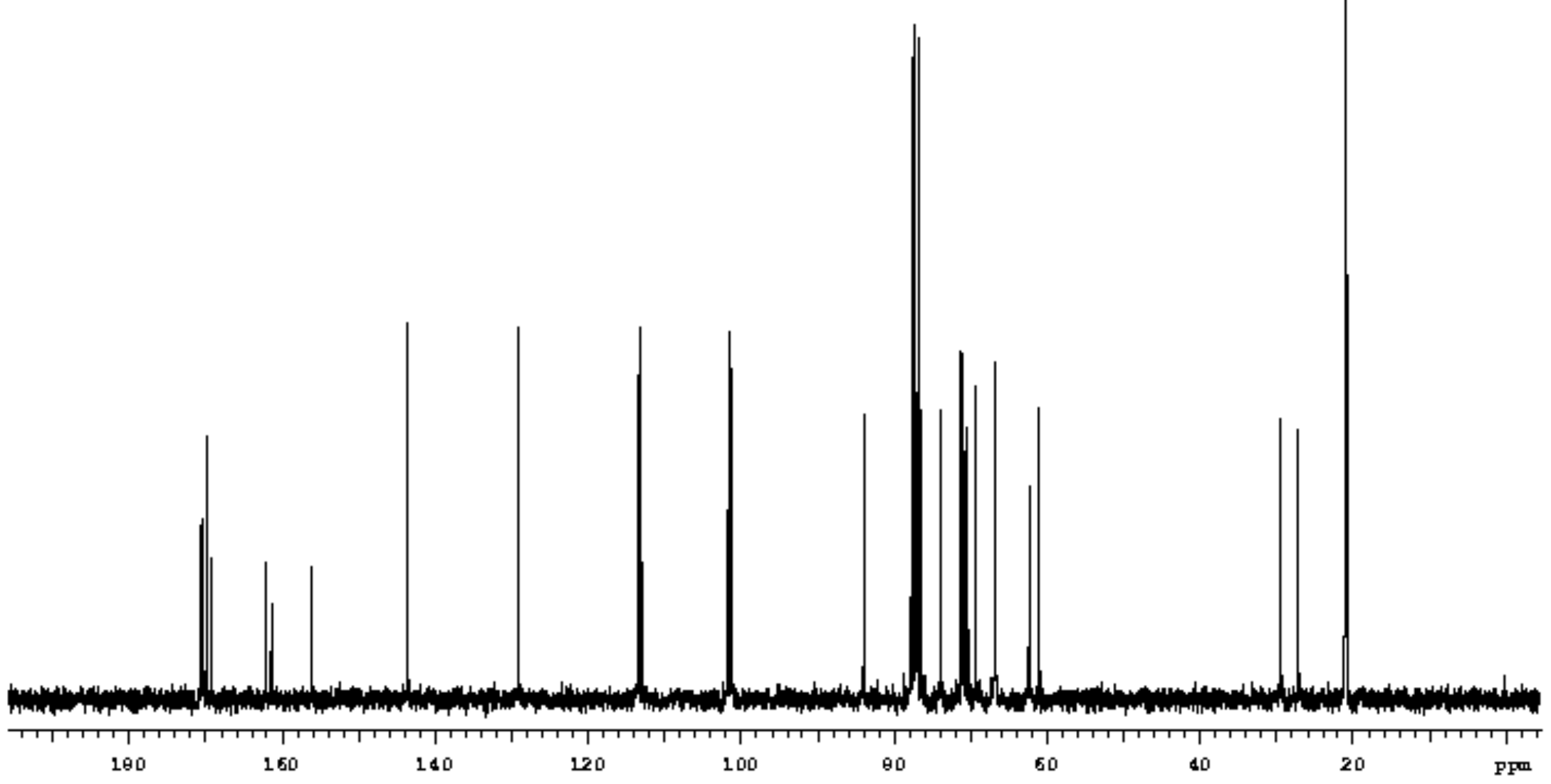



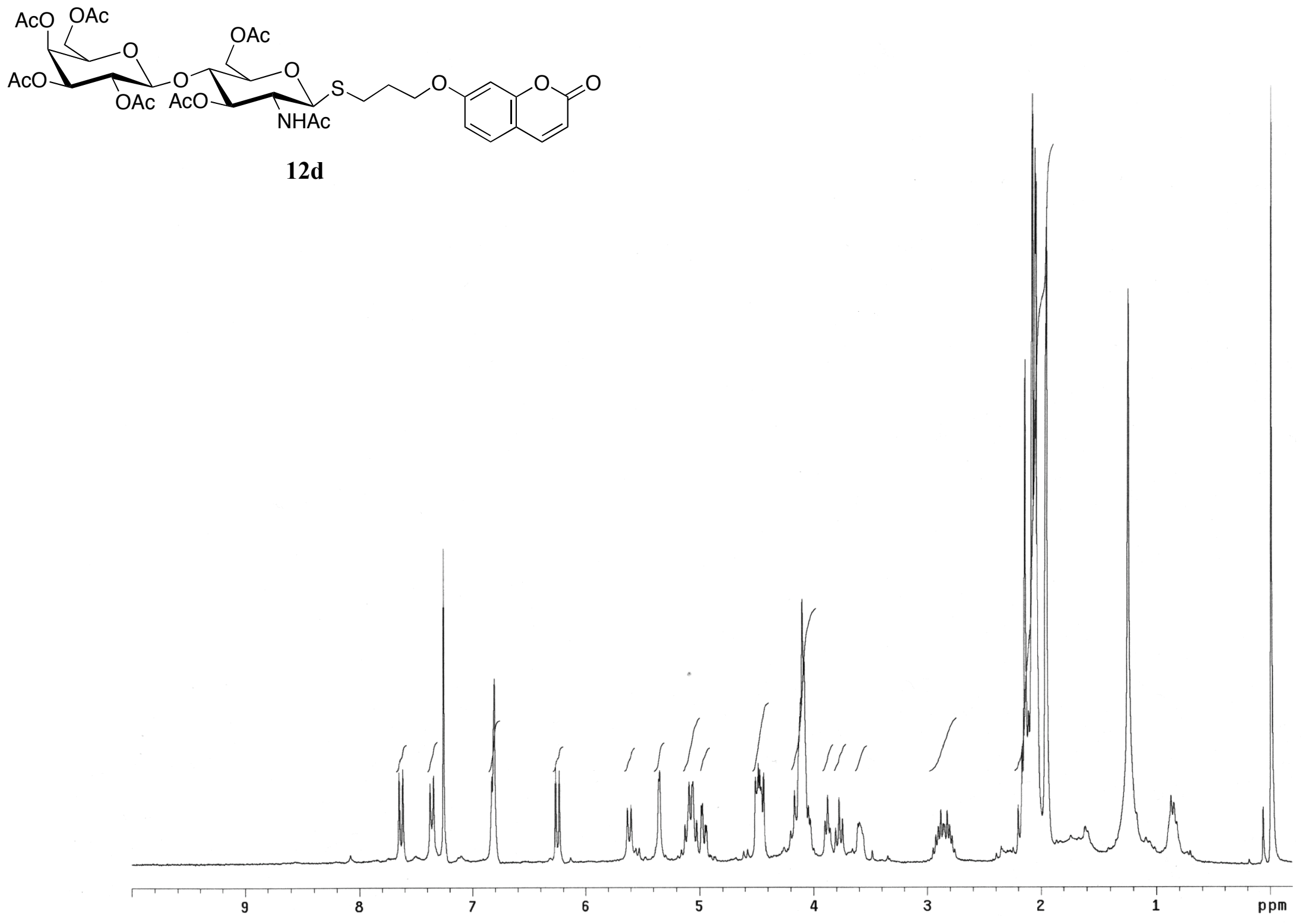


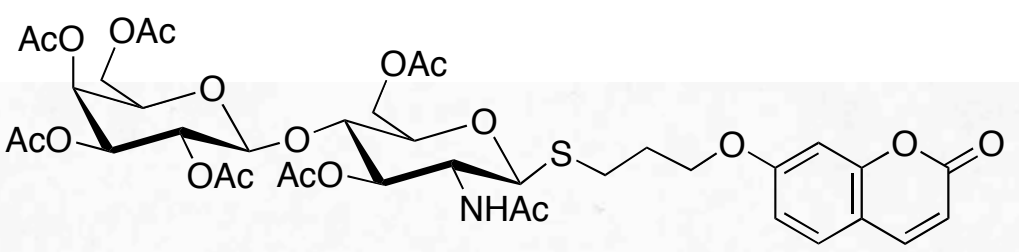

12d

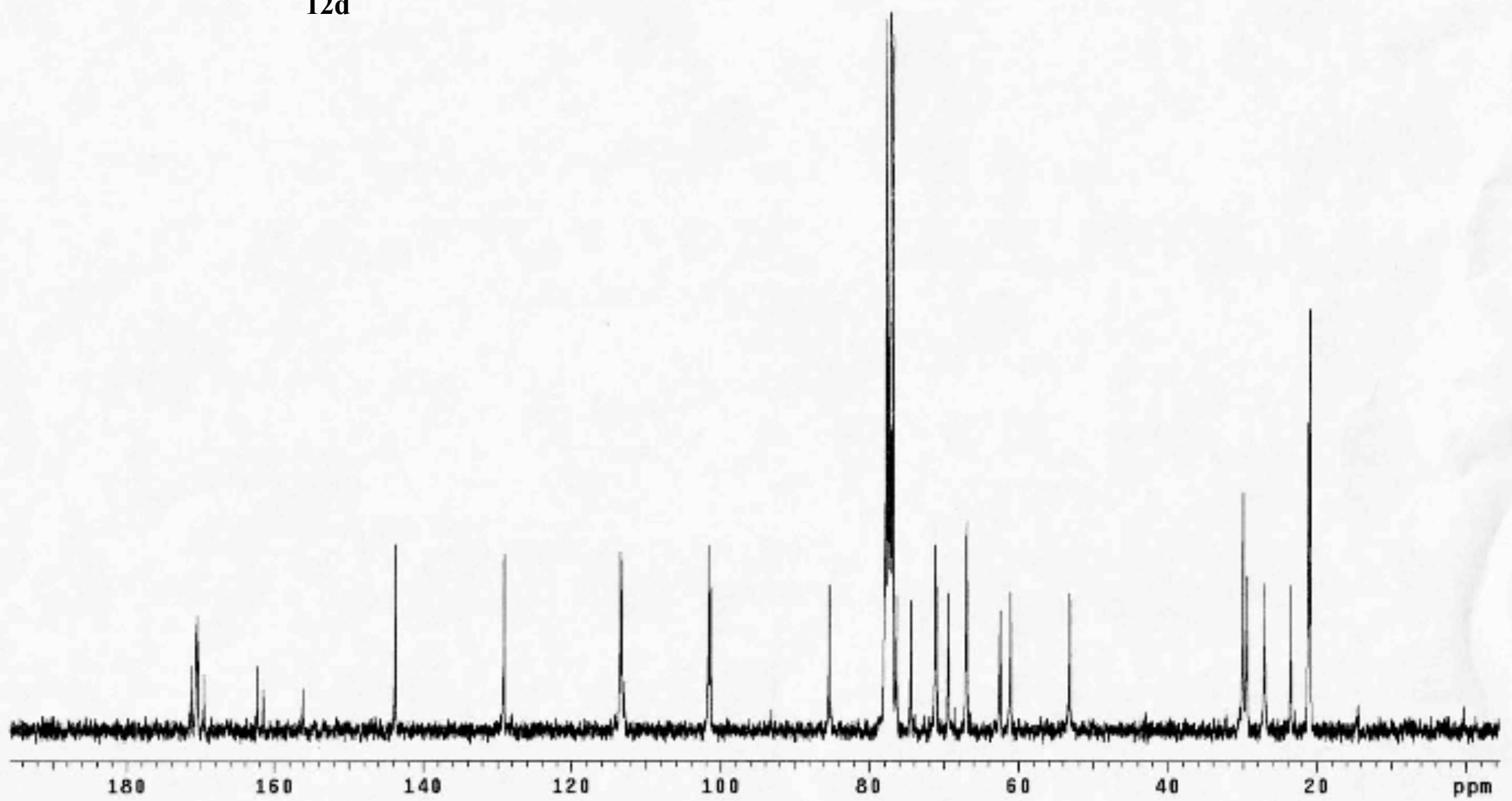



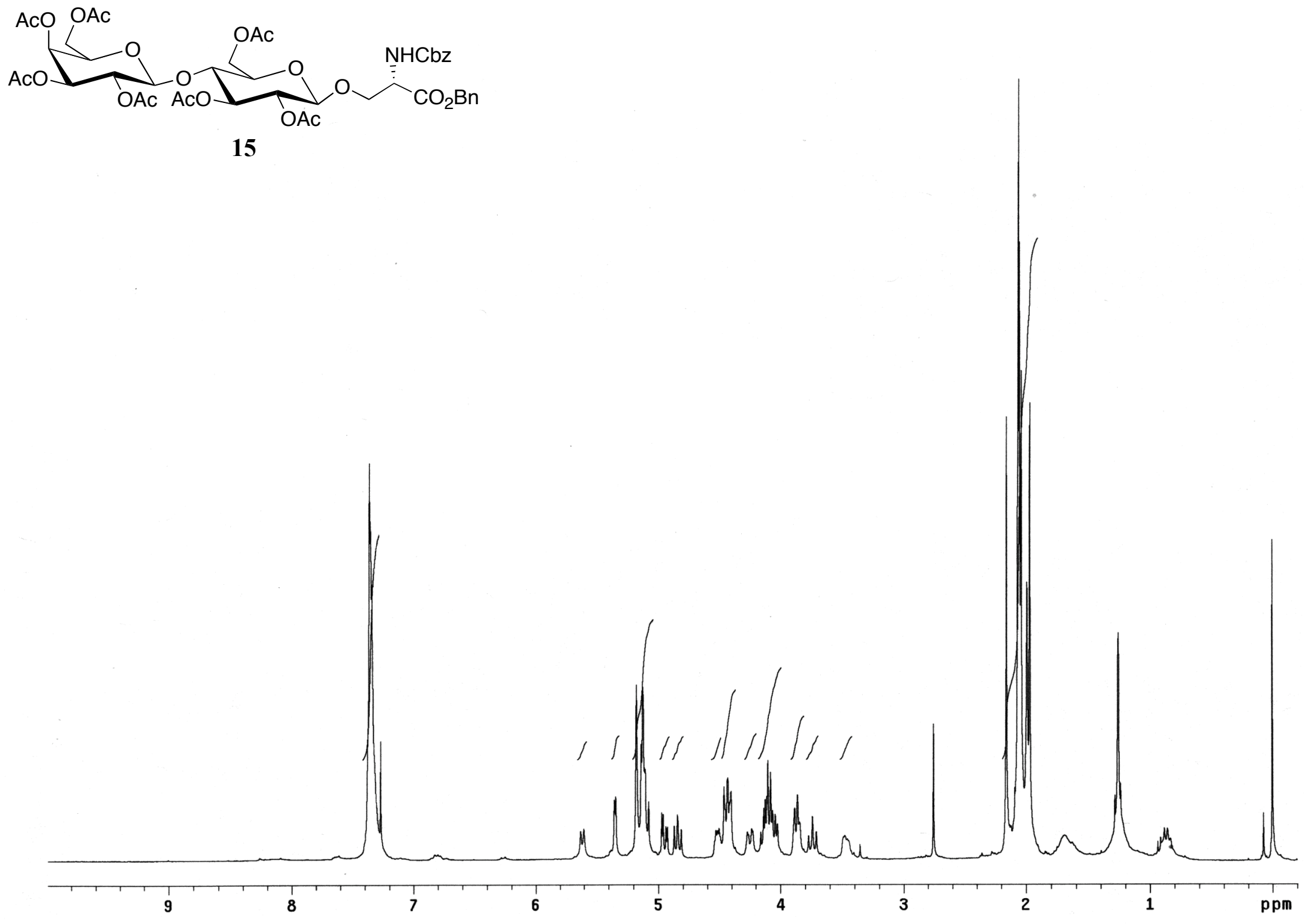


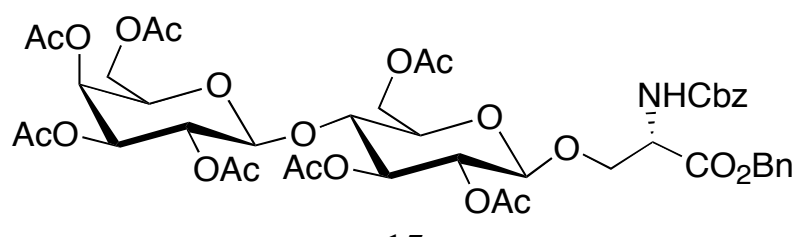

15

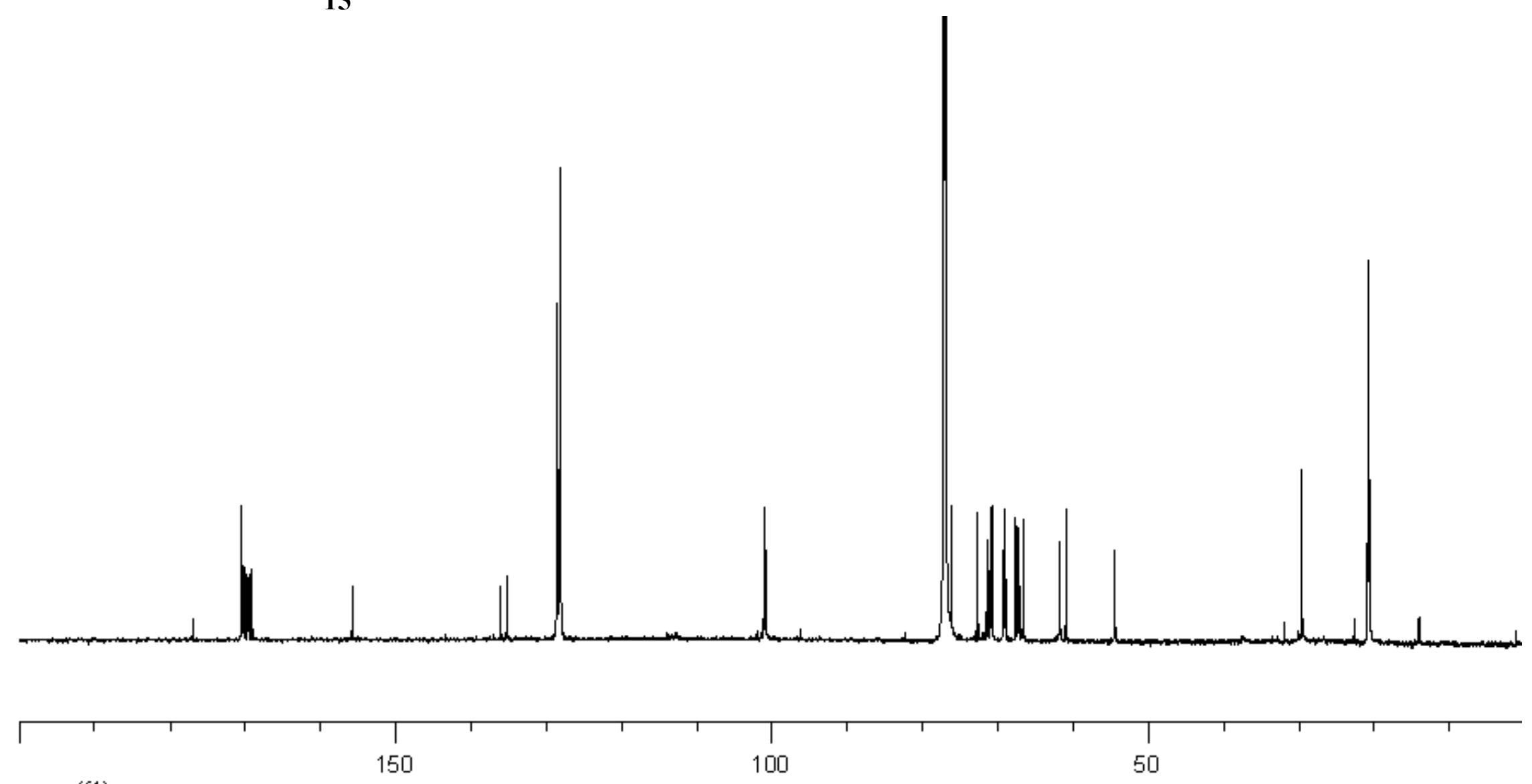

ppm (f1) 